\title{
Mouse Cytoplasmic Dynein Intermediate Chains: Identification of New Isoforms, Alternative Splicing and Tissue Distribution of Transcripts
}

\author{
Anna Kuta ${ }^{1}$, Wenhan Deng ${ }^{2}$, Ali Morsi El-Kadi ${ }^{2}$, Gareth T. Banks ${ }^{1}$, Majid Hafezparast ${ }^{2}$, K. Kevin Pfister ${ }^{3}$, \\ Elizabeth M. C. Fisher ${ }^{1 *}$
}

1 Department of Neurodegenerative Disease, UCL Institute of Neurology, London, United Kingdom, 2 Biochemistry and Biomedical Science, School of Life Sciences, University of Sussex, Brighton, United Kingdom, 3 Cell Biology Department, School of Medicine, University of Virginia, Charlottesville, Virginia, United States of America

\begin{abstract}
Background: Intracellular transport of cargoes including organelles, vesicles, signalling molecules, protein complexes, and RNAs, is essential for normal function of eukaryotic cells. The cytoplasmic dynein complex is an important motor that moves cargos along microtubule tracks within the cell. In mammals this multiprotein complex includes dynein intermediate chains 1 and 2 which are encoded by two genes, Dync1i1 and Dync1i2. These proteins are involved in dynein cargo binding and dynein complexes with different intermediate chains bind to specific cargoes, although the mechanisms to achieve this are not known. The DYNC1I1 and DYNC112 proteins are translated from different splice isoforms, and specific forms of each protein are essential for the function of different dynein complexes in neurons.

Methodology/Principal Findings: Here we have undertaken a systematic survey of the dynein intermediate chain splice isoforms in mouse, basing our study on mRNA expression patterns in a range of tissues, and on bioinformatics analysis of mouse, rat and human genomic and cDNA sequences. We found a complex pattern of alternative splicing of both dynein intermediate chain genes, with maximum complexity in the embryonic and adult nervous system. We have found novel transcripts, including some with orthologues in human and rat, and a new promoter and alternative non-coding exon 1 for Dync1i2.

Conclusions/Significance: These data, including the cloned isoforms will be essential for understanding the role of intermediate chains in the cytoplasmic dynein complex, particularly their role in cargo binding within individual tissues including different brain regions.
\end{abstract}

Citation: Kuta A, Deng W, Morsi El-Kadi A, Banks GT, Hafezparast M, et al. (2010) Mouse Cytoplasmic Dynein Intermediate Chains: Identification of New Isoforms, Alternative Splicing and Tissue Distribution of Transcripts. PLoS ONE 5(7): e11682. doi:10.1371/journal.pone.0011682

Editor: Mark R. Cookson, National Institutes of Health, United States of America

Received April 18, 2010; Accepted June 20, 2010; Published July 21, 2010

Copyright: (C) 2010 Kuta et al. This is an open-access article distributed under the terms of the Creative Commons Attribution License, which permits unrestricted use, distribution, and reproduction in any medium, provided the original author and source are credited.

Funding: These authors are supported by the Wellcome Trust, the ENDOCYTE Research and Training Network funded by the European Union and the UK Medical Research Council and the National Institute of General Medical Science (National Institutes of Health). The funders had no role in study design, data collection and analysis, decision to publish, or preparation of the manuscript.

Competing Interests: The authors have declared that no competing interests exist.

*E-mail: e.fisher@prion.ucl.ac.uk

\section{Introduction}

To transport cargoes within eukaryotic cells, energy dependent motors run along tracks in the cell formed by either the microtubule network (dynein and kinesin motors) or the actin cytoskeleton (used by myosin motors). The motor proteins associated with microtubules can be classified as moving towards the growing 'plus' end of microtubules (anterograde transport in axons) or moving towards the 'minus' end of microtubules (retrograde transport in axons). While several kinesin motors are responsible for anterograde transport, the cytoplasmic dynein complex is the single main retrograde transport motor.

Two cytoplasmic dynein complexes have been identified, of which cytoplasmic dynein 1 is the most abundant in cells, while cytoplasmic dynein 2 takes part in intraflagellar transport $[1,2,3]$. Cytoplasmic dynein 1 is a multisubunit complex of $\sim 1.5 \mathrm{MDa}$; in mammals this complex is thought to consist of a homodimer of heavy chains (encoded by a single gene Dync1h1); two intermediate chains (encoded by two genes Dync1i1, Dync1i2); light-intermediate chains (encoded by two genes Dync1li1, Dync1li2); light chains (thought to be encoded by three gene families, containing six different genes (Dynlt1, Dynlt3, Dynlrb1, Dynlrb2, Dynll1, Dynll2)) $[1,4,2,3]$. The core of the dynein complex is a homodimer of the heavy chains which binds to microtubules and enables cytoplasmic dynein to move in an ATP dependent manner [5,6]. The other dynein subunits are thought to associate in the complex as homodimers and to maintain the stability of the complex, to modulate its activity, and to interact with accessory and cargo proteins $[7,8,3,9]$.

The interaction and regulation of cytoplasmic dynein 1 with its cargos is poorly understood; the intermediate chain proteins DYNC1I1 (IC1) and DYNC1I2 (IC2) play roles in cargo binding and are involved in cargo specificity [10,7]. It is also clear that interactions of the dynein complex with cargoes often requires 
the presence of the dynactin complex - another large, multisubunit complex that binds to both the intermediate chains of the dynein complex to modulate dynein-cargo interactions, and to microtubules to modulate the movement of dynein $[11,12]$. However, IC1 and IC2 may also interact directly with protein cargos including beta-catenin [13], casein kinase II [14], neurofilaments [15], kinesin light chains 1 and 2 [16] and huntingtin [17].

IC1 and IC2 share $69 \%$ protein identity and have a molecular weight of approximately $74 \mathrm{kDa}[18,2,3]$, and can form homo- or heterodimers in overexpression assays [19]. They interact with the dynein light chains and the p150 subunit of dynactin at the Nterminus and with the heavy chains through WD40 repeats at the intermediate chain C-terminus [20,2,3]. Both proteins are expressed in multiple splice isoforms - alternative splicing occurs at their N-terminal regions and tissue- and development-specific isoforms have been described in human, rat and mouse (for brief discussion and original references see [21,22,23,3]. The functional importance of individual splice isoforms is highlighted by the discovery that in rat one dynein complex containing a IC1 isoform, specifically binds nerve growth factor receptor TrkBcontaining endosomes in neurons [10], thus this isoform likely confers cargo specificity on the dynein complex and is important for neuronal function. Conversely, dynein complexes containing IC2 are important for transport of TrkA signalling endosomes in PC12 cells [10].

Since this evidence indicates that alternatively spliced intermediate chain isoforms are central to dynein complex function and cargo specificity, we undertook a survey of their expression in a range of mouse tissues, using both RNA studies and bioinformatics analysis including comparison with human and rat data. Here we show (1) new splice isoforms for both genes, (2) a systematic survey of expression of different intermediate chain splice isoforms in a range of adult and embryonic mouse tissues, including different brain regions and spinal cord, (3) and we also identify transcription of Dync1i2 from a new upstream promoter that results in an alternative non-coding exon 1 and a second set of Dync1i2 transcripts.
This survey serves as the basis for a thorough functional dissection of the dynein intermediate chains in mouse and their likely roles in binding different cargoes in a cell-specific and development-specific manner, particularly within the nervous system.

\section{Results}

To determine the splice isoform patterns of the mouse dynein intermediate chain 1 and 2 genes, we used a combination of reverse-transcription polymerase chain reactions (RT-PCRs) of mouse RNA, literature searching and bioinformatics analysis of mouse (version mm9), rat (rn4) and human (hg19) data in the UCSG Genome Browser. We note that because different nomenclatures have already been applied to the few previously described mouse and rat dynein intermediate chain isoforms (Table 1), for clarity we base our nomenclature on that of Pfister, Vaughan, Vallee, and colleagues who described three rat protein isoforms of DYNC1I1 (IC1A, 1B, 1C) and three isoforms of DYNC1I2 (IC2A, 2B, 2C) [21,22,23]. In line with current gene nomenclature rules, we also include a UCSC or Ensembl accession number relating to a 'reference' cDNA sequence for each isoform described below.

\section{Analysis of the splicing pattern of mouse Dync1i1}

Dyncli1 is located on chromosome 6 band qA1, spanning over 302,000kb between base pairs 5,675,739 and 5,978,030 (Ensembl, March 2010, transcript ENSMUST00000115555), and exons 1 and exon 17 contain the 5'UTR and 3'UTR respectively; the start methionine is encoded in exon 2 (the exon-intron boundaries of the mouse genomic locus are given in Table S1). We found no evidence for alternative first or last exons. A conserved miRNA binding site for miR155 lies in the $3^{\prime} \mathrm{UTR}$ as determined by TargetScan.

To survey the Dync1i1 splicing pattern spatially and temporally in mouse, we extracted total RNA from a set of tissues: adult male and female: brain, spinal cord, ovary, testis, spleen, lung, kidney, heart, intestine, muscle, liver; and embryonic E17.5: whole embryos,

Table 1. Mouse dynein intermediate chain splice isoforms.

\begin{tabular}{|c|c|c|c|c|c|c|}
\hline \multicolumn{7}{|c|}{ Mouse dynein intermediate chain 1 (Dync1i1) } \\
\hline $\begin{array}{l}\text { Mouse } \\
\text { isoform } \\
\text { name }\end{array}$ & $\begin{array}{l}\text { GenBank } \\
\text { accession } \\
\text { number }\end{array}$ & $\begin{array}{l}\text { UCSC and/or ENSEMBL } \\
\text { accession number for 'reference } \\
\text { sequence' for each isoform }\end{array}$ & $\begin{array}{l}\text { Homologous published rat isoforms } \\
{[21,22] \text { and previously described }} \\
\text { mouse isoforms, in italics [34] }\end{array}$ & Exons & $\begin{array}{l}\text { Exon } 4 \text { alter- } \\
\text { native splice } \\
\text { site }\end{array}$ & $\begin{array}{l}\text { Number } \\
\text { of amino } \\
\text { acids }\end{array}$ \\
\hline \multicolumn{2}{|l|}{ Dync1i1.A } & ENSMUST00000115555 & $\begin{array}{l}\text { IC } 1 \mathrm{~A} \\
\text { Dncila }\end{array}$ & 1 to 17 & AS1 & 645 \\
\hline Dync1i1.B & NM_010063.3 & uc009awn.1, ENSMUST00000115559 & $\begin{array}{l}\text { IC 1B } \\
\text { Dncilc }\end{array}$ & 1 to 17 & AS2 & 628 \\
\hline \multicolumn{2}{|l|}{ Dync1i1.D } & ENSMUST00000115556 & Dncild & 1 to 17 & AS3 & 617 \\
\hline \multicolumn{2}{|l|}{ Dync1i1.E } & GU992206* & & 1 to 4,6 to 17 & AS1 & 625 \\
\hline \multicolumn{2}{|l|}{ Dync1i1.C } & ENSMUST00000115554 & $\begin{array}{l}\text { IC 1C } \\
\text { Dncile }\end{array}$ & 1 to 4,6 to 17 & AS2 & 608 \\
\hline \multicolumn{2}{|l|}{ Dync1i1.F } & GU992207* & & 1 to 4,6 to 17 & AS3 & 597 \\
\hline \multicolumn{7}{|c|}{$\begin{array}{l}\text { The mouse gene nomenclature convention is to name each isoform: genename_GenBank transcript number. We have used the unofficial names Dync1i1.A, Dync1i1.B, } \\
\text { etc., here to show their correspondence to the widely used IC } 1 \mathrm{~A}, 1 \mathrm{~B}, 1 \mathrm{C} \text { previously described in rat [22]. However, we also show the correspondence to GenBank mouse } \\
\text { cDNAs, UCSC known genes and Ensembl transcripts. As Dync1i2 has two alternative non-coding first exons, we cannot determine which Dync1i2 isoforms correspond to } \\
\text { the previously described rat isoforms IC2A, } 2 \mathrm{~B}, 2 \mathrm{C} \text {, hence these are in parentheses [22]. Crackower and colleagues noted the presence of some mouse splice isoforms } \\
\text { and we also show to their notation from their } 1999 \text { publication Dnci1a, c, d, e in italics [34]. We number exons from } 1 \text { to } 17 \text { for Dync } 1 i 1 \text {, and from } 1 \text { to } 18 \text { for Dync1i2 } \\
\text { including either exon } 1 \text { a or exon } 1 \mathrm{~b} \text {, and exon } 3 \mathrm{~b} \text {. } \\
\text { *first described in this paper. }\end{array}$} \\
\hline
\end{tabular}


brain and spinal cord. We synthesised cDNA from oligo dT primers and then amplified PCR products using the primers DIC1_Ex 1 for and DIC1_Ex $17 \mathrm{rev}$ (Table 2) that bind within the first and last exons of the longest mouse Dync1i1 sequence in the UCSC database, uc009awn.1 (RefSeq sequence NM_010063.3).

We found a complex pattern of amplified fragments in brain, spinal cord, and the embryonic tissues, one homogenously sized amplicon in testis and ovary, and no amplification detectable from spleen, lung, kidney, heart, intestine, muscle or liver. PCR products were sequenced and the amplicon in testis and ovary was found to be a single transcript, here named isoform Dync1i1.C (Figure 1). The sequences from the adult brain, spinal cord, and E17.5 embryonic tissues were unreadable, presumably due to the presence of multiple splice isoforms. To further investigate, the PCR products from brain and spinal cord were subcloned and sequenced to determine which exons were present in individual transcripts.

From sequencing 62 brain and 14 spinal cord subclones and from a bioinformatics analysis of mouse, human and rat, we found six different transcripts, including two novel isoform (here named Dync1i1.E and Dync1i1.F) (Figure 1). Exon 5 (60 bp) is absent from three of these transcripts (1.C, 1.E, 1.F). We also found, that exon 4 has three possible alternative splice sites, in agreement with human bioinformatics, while only two splice sites were detected experimentally in rat.

To determine which individual isoforms were present in dissected brain regions (cortex, cerebellum, brain stem, hippocampus, olfactory bulb) and other tissues we designed a panel of isoform specific primer pairs (Table 2) and surveyed tissues for the presence or absence of the six Dyncli1 isoforms (for example, Figures 2, S1). We found our amplification results showed reproducible differences in the patterns of intensity of individual amplicons in different tissues; for example, compare amplification of brainstem and olfactory bulb in Figure 2B. Although RT-PCR is not a quantitative method these robust and repeatable amplification patterns probably indicate differences in relative expression of the isoforms in different brain regions. We went on to use nested PCRs to confirm the presence of some individual amplicons which had similar lengths for initial PCRs (for example,

Table 2. Primer pairs used to amplify individual Dync1i1 splice isoforms (Figure 1).

\begin{tabular}{lll}
\hline & & \\
\hline Primer pair & $\begin{array}{l}\text { Isoform } \\
\text { detected }\end{array}$ & $\begin{array}{l}\text { Predicted size of } \\
\text { amplicon }\end{array}$ \\
\hline DIC1_Ex 1 for and DIC1_R rev & Dync1i1.A & $531 \mathrm{bp}$ \\
& Dync1i1.B & $480 \mathrm{bp}$ \\
& Dync1i1.D & $447 \mathrm{bp}$ \\
& Dync1i1.E & $471 \mathrm{bp}$ \\
& Dync1i1.C & $420 \mathrm{bp}$ \\
& Dync1i1.F & $387 \mathrm{bp}$ \\
DIC1_Ex 1 for and DIC1_AS4 rev & Dync1i1.A & $371 \mathrm{bp}$ \\
& Dync1i1.B & $320 \mathrm{bp}$ \\
DIC1_Ex 1 for and DIC1_5 rev & Dync1i1.A & $477 \mathrm{bp}$ \\
& Dync1i1.B & $426 \mathrm{bp}$ \\
& Dync1i1.D & $393 \mathrm{bp}$ \\
DIC1_Ex 1 for and DIC1_iso14 rev & Dync1i1.E & $447 \mathrm{bp}$ \\
& Dync1i1.C & $396 \mathrm{bp}$ \\
& Dync1i1.F & $363 \mathrm{bp}$ \\
DIC1_1.1 for and DIC1_5 rev & Dync1i1.A & $206 \mathrm{bp}$ \\
DIC1_1.1 for and DIC1_iso14 rev & Dync1i1.E & $155 \mathrm{bp}$ \\
\hline doi:10.1371/journal.pone.0011682.t002 &
\end{tabular}

Figures 3, S2). A summary of our findings is presented in Table 3 and Figure 1. In addition we note that for isoform:

Dync1i1.A. This isoform was detected originally at low levels in adult brain by RT-PGR and was then cloned and sequenced. This isoform corresponds to the previously described protein, DYNC1I-1A (IC1A) in rat [6,2,3]. We confirmed the presence of this isoform in a specific RT-PCR using primers DIC1_1.1 for and DIC1_5 rev to detect a 206 bp amplicon in multiple brain regions and spinal cord, and embryonic tissues but not other tissues in mouse (Figure 3, Table 3). Database searches showed orthologous isoforms in human (uc003uoc.3) and rat (NM_019234.1).

Dync1i1.B. This isoform was detected in 33/62 subclones from adult mouse brain and 9/14 subclones from adult mouse spinal cord. It is identical to the mouse cDNA uc009awn.1 and corresponds to the previously described protein, IC1B in rat [21,23]. Dynclil.B is expressed in the nervous system and embryonic tissues only (Table 3). Database searches found an orthologous full-length cDNA in human (uc003uod.3), but only ESTs in rat (CB703089, CB747457).

Dync1i1.D. This isoform was detected in 16/62 subclones from adult mouse brain and 5/14 subclones from adult mouse spinal cord, and was amplified in these tissues and embryonic tissues using two different sets of primer pairs (DIC1_Ex 1for and DIC1_R rev, DIC1_Ex 1 for and DIC1_5 rev, Table 2) but did not amplify in other tissues. This isoform has been found as a human EST (DA392898) but is not present in the current rat databases.

Dync1i1.E. This novel isoform has not been characterized previously. It was not detected during the initial cloning analysis nor was it present amongst the UCSC mouse sequences (mm9). However, by database searching we found a human cDNA (uc003uoe.3) and a rat EST (CB712052) in which AS1 in exon 4 is present and exon 5 is removed. Therefore we designed PCR primers (DIC1_1.1 for and DIC1_iso14 rev) to detect only this isoform in mouse. In all brain tissues examined plus spinal cord and embryonic tissues, the expected 155 bp product was amplified (for example see Figure S2). This isoform was not found outside of brain or spinal cord, or embryonic tissues. The GenBank accession number obtained for this sequence is GU992206 (Table 1).

Dync1i1. C. This isoform was detected in 12/62 subclones from adult mouse brain and unlike the other Dyncli1 transcripts it was found in ovary and testis, but not other tissues (in amplification with the primer pairs DIC1_Ex 1 for and DIC1_R rev or DIC1_Ex 1 for and DIC1_isol4 rev) (Figure S1). It corresponds to the previously described protein IC $1 \mathrm{C}$ in rat. This isoform has a human full-length orthologue, uc003uob.2, and is homologous to two rat ESTs CB616735, CB713291.

Dync1i1.F. This novel isoform was detected in $1 / 62$ subclones from brain, and amplified at low levels throughout the nervous system and embryonic tissues, with primer pairs DIC1_Ex 1 for and DIC1_R rev, and DIC1_Ex 1 for and DIC1_iso14 rev, but it does not amplify in other tissues. We did not find orthologous human or rat sequences in the databases. This is a low abundance isoform in the tissues assayed and it remains unknown if it is a functional transcript. The GenBank accession number obtained for this sequence is GU992207 (Table 1).

\section{Analysis of the splicing pattern of mouse Dync1i2}

Dync1i2 maps to chromosome 2, band C2, spanning over $51,000 \mathrm{~kb}$ between base pairs 71,049,798 and 71,101,360 (Ensembl, March 2010, transcript ENSMUST00000112140). The start methionine lies in exon 2. We did not detect any evidence for 


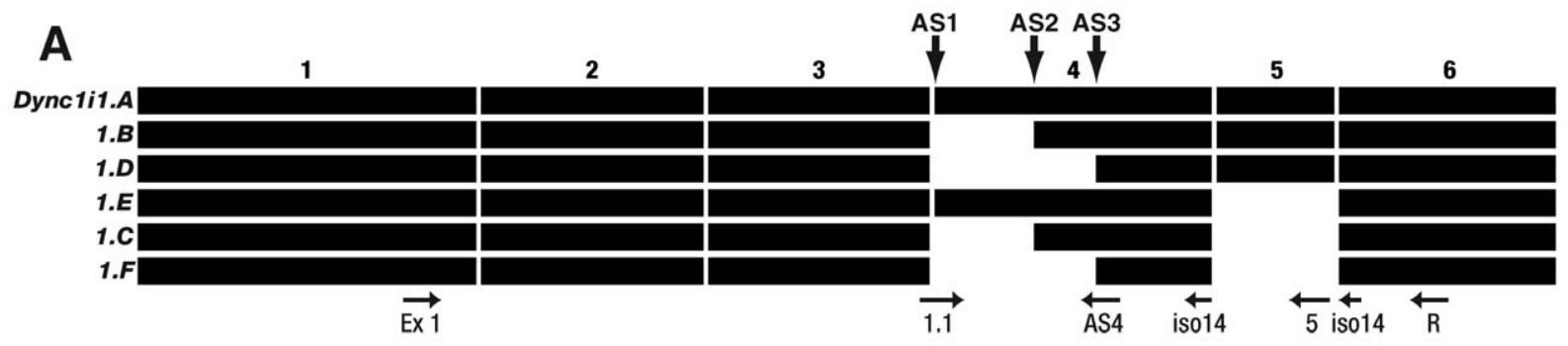

B

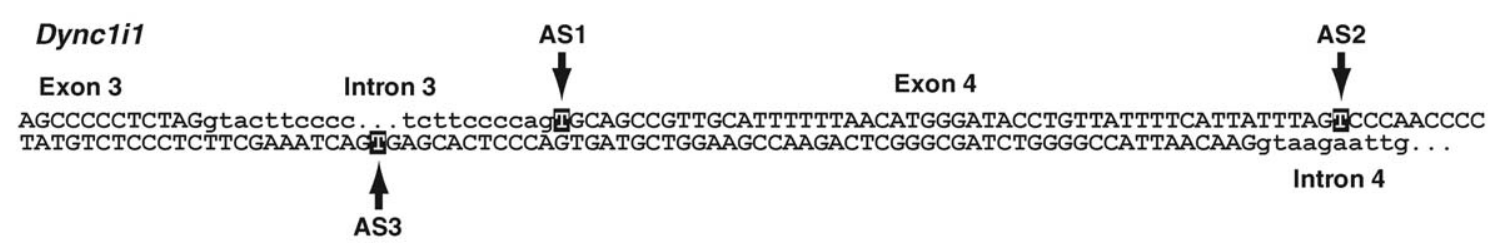

Figure 1. Splicing pattern of mouse dynein intermediate chain 1 gene. A. Summary of alternative splicing in Dyncli1, showing splice variants Dync1i1.A to Dync1i1.F, and the first 6 exons (numbered 1, 2, 3, 4, 5, 6); primer binding sites used for isoform specific RT-PCRs are as indicated (Table 2, S2), and AS1, 2 and 3 are the alternative splice sites in exon 4. Exons are drawn to scale. B. Alternative splice sites in Dync1i1 exon 4. The nucleotide in bold is the first base pair of the exon. Bases in lower case are intronic, bases in upper case are exonic. doi:10.1371/journal.pone.0011682.g001

microRNA binding sites in the 3'UTR of the gene (the exon-intron boundaries of the mouse genomic locus are given in Table S1).

Bioinformatics analysis of the Dync1i2 gene in mouse, human and rat showed that in all three species this gene produces two sets of transcripts containing different first exons, indicating the presence of two independent promoters; this is corroborated by analysis with the DBTSS track of the UCSC Genome Browser which distinguishes two active promoters, adjacent to two noncoding exons in the three species. We named the two alternative exons la and 1b. Exon la is upstream of Exon $1 \mathrm{~b}$ and they are separated by $\sim 125 \mathrm{bp}$ of genomic DNA with no overlap between the exons. We found no transcript that contained both exons. We note that the start methionine remains the same in all Dync1i2 transcripts as this lies in exon 2.

To survey Dyncli2 splicing we designed two RT-PCRs based on sequences in the UCSC Genome Browser (exon 1a: uc008kah.1, uc008kai.1; exon 1b: uc008kak.1, uc008kaj.1). We amplified sequence using forward primers from either exon la (DIC2_Exla for) or exon 1b (DIC2_Ex1b for) and one reverse primer lying in the last exon of the gene (DIC2_Ex18 rev) (Primer sequences used to determine the splicing patterns of Dync1i1 and Dync1i2 are given in Table S2). Amplified products of Dync1i2 from both primer pairs were purified and sequenced.

In all non-neuronal and non-embryonic tissues, we found that primers specific for either exon la or exonlb yielded a single isoform designated 2C in this paper i.e. Dync1i2(1a).C or Dync1i2(1b).C (Figure 4). However, the amplification patterns in the nervous system and embryonic tissues were complex and we were unable to sequence the mix of PCR products from these tissues. To determine which isoforms of Dync1i2 were expressed in these tissues, the RT-PCR products were subcloned and sequenced; subsequent analysis, revealed a total of 11 different isoforms each having either exon $1 \mathrm{a}$ or exon $1 \mathrm{~b}$ at the start of the transcript (Table 1, Figure 4). This Includes two novel isoforms (Dync1i2(1a).D and Dync1i2(1b).D, Figure 4) that were detected during RT-PCR analysis.

Based on the information from individual subclones derived from both exons $1 \mathrm{a}$ and $1 \mathrm{~b}$, we then designed isoform specific primer pairs to survey all mouse tissues previously described; we used nested PCRs to confirm the presence of some individual amplicons whch had similar lengths in our intial PCRs (Table 4, Figure 5, 6).

We also detected a novel exon of $51 \mathrm{bp}$, here designated exon $3 \mathrm{~b}$, which lies downstream of exon 3; this has two alternative splice sites (Figure 4). Exon 3b does not align to human genomic sequence from either dynein intermediate chain gene but does appear to have an equivalent sequence in rat genomic DNA in Dync1i2. In mouse, when we align exon 3b with Dync1i1 genomic sequence, aligning either DNA or the translations, we are unable to detect a likely equivalent exon, thus this exon $3 \mathrm{~b}$ appears specific for Dyncli2 in mouse and rat (and see Discussion).

\section{Summary of mouse Dync1i2 alternative splicing}

A summary of our findings is presented in Table 5, Figure 4. We found Dync1i2 has 11 isoforms: six including exon la, five including exon $1 \mathrm{~b}$; isoforms with the same exon content other than exon $1 \mathrm{a}$ and $1 \mathrm{~b}$ have similar but not identical expression patterns (Table 5). In addition we note that for isoform:

Dync1i2(1b).D. This novel isoform was identified as an unexpected larger $340 \mathrm{bp}$ product that was produced in addition to the expected Dync1i2(1b).E (325 bp) amplicon when some but not all nervous system tissues were amplified with the primers DIC2_Ex 1b for and DIC2_2.1 rev. The fragment was sequenced and found to contain the new exon, 3b, which is flanked by consensus splice sites and has two alternative splice acceptor sites. We did not find an alignment of exon $3 b$ in the human genomic dynein intermediate chain genes. However, in rat, while no equivalent transcripts are in the databases, we did detected a $48 \mathrm{bp}$ almost perfect alignment to rat genomic sequence in the expected position within rat intron 3 , except that an internal $3 \mathrm{bp}$ (GAG, encoding glutamic acid), is absent. The complete 48 bp can be transcribed into a 16 amino acid peptide that maintains the open reading frame of the protein and thus this is likely to be rat exon 3b. Dync1i2.D is the longest Dync1i2(1b) transcript we can detect, being 2,478 bp in length. This isoform does not so far have orthologs in human or rat. GenBank accession number obtained for this sequence is GU992211 (Table 1).

Dync1i2(1a).D. This novel isoform was amplified using primers spanning Exon la and exon DIC2_Ex la for and 
A
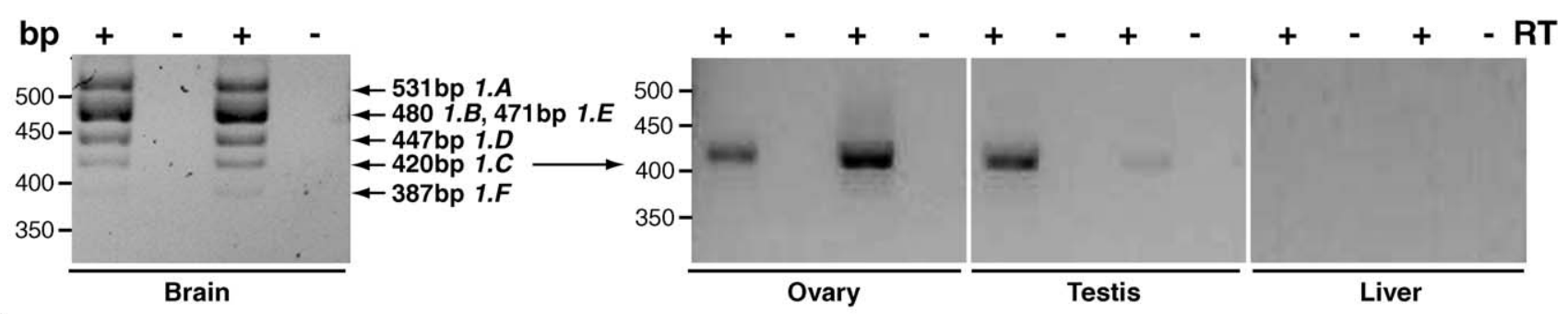

B
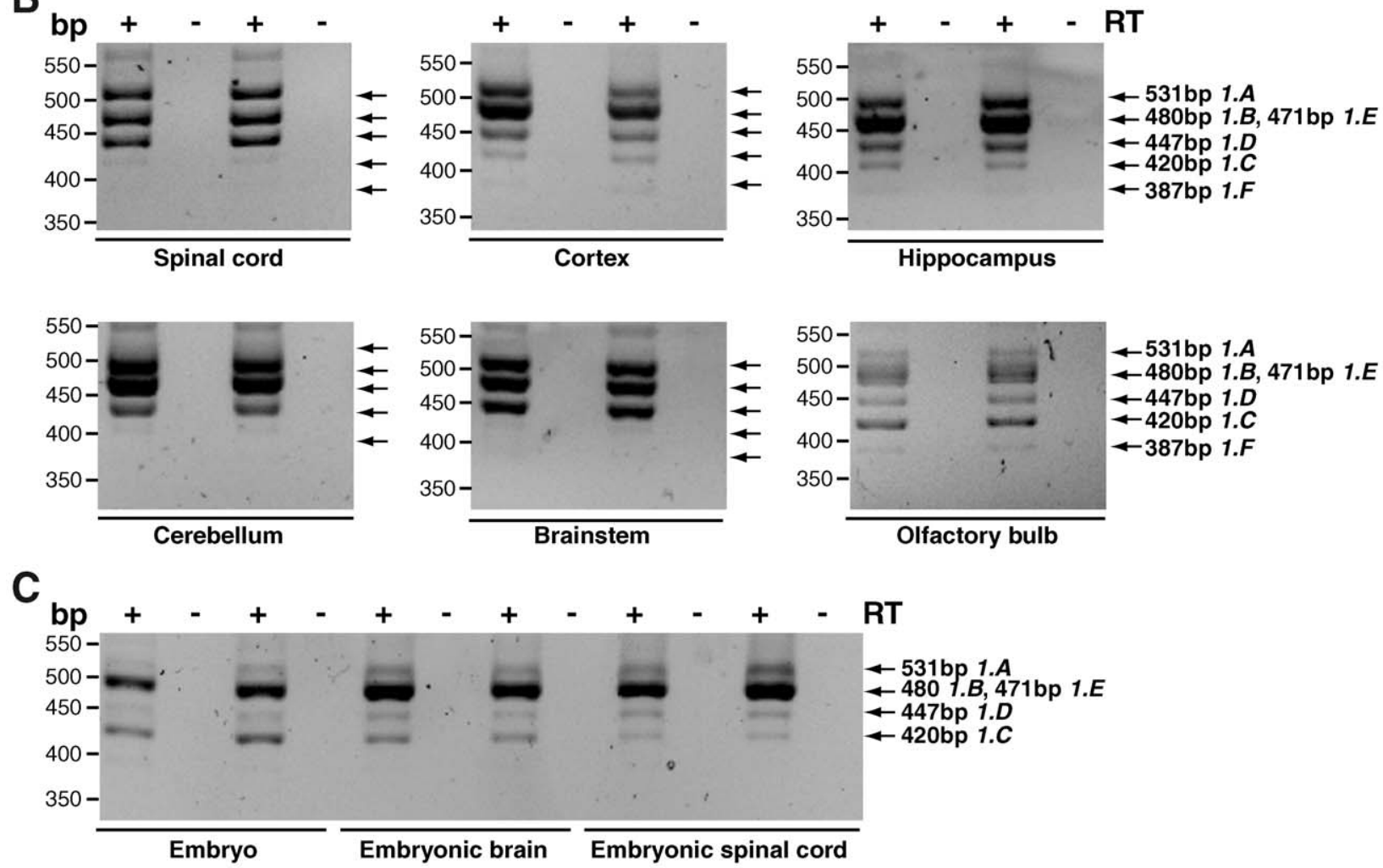

Figure 2. Amplification of different isoforms of Dync1i1 in mouse tissues using one primer pair. Isoforms of Dync1i1 were amplified in mouse tissues using primer pair DIC1 Ex1 for and DIC1_R rev which produces six products: Dync1i1.A (531 bp), Dync1i1.B (480 bp), Dync1i1.E (471 bp), Dync111.D (447 bp), Dync1i1.C (420 bp), Dync1i1.F (387bp). Dync1i1.B (480 bp) and Dync1i1.E (471 bp) are not resolved due to similar length of PCR products, and were subsequently individually confirmed as present using isoform specific primer pairs (Table 2), for example see amplification of Dync1i1.E using isoform specific primer pair DIC1_1.1 for and DIC1_5 rev (Figure S2). Note that in some tissues amplification products are faint, and so results were confirmed with other primer pairs as indicated in Table 2; for example, see amplification of Dync1i1.A in Figure 3. In some tissues we also saw a high molecular weight fragment running at approximately $560 \mathrm{bp}$ (for example see spinal cord or cerebellum); this may represent another isoform but we were unable to clone or sequence this fragment. A. Adult tissues: brain, ovary, testis and liver. In brain 6 amplicons are detected as shown. In ovary and testis we detect isoform Dync1i1.C only (420bp). No product is amplified in liver. B. Adult neuronal tissues: in spinal cord, cortex, hippocampus, cerebellum, brainstem and olfactory bulb, between four and six amplicons (for example compare brainstem and olfactory bulb) could be detected as shown. C. Embryonic tissues: five amplicons are detected as shown. ' + ' lanes are CDNA, ' - ' lanes control for genomic DNA contamination and have no reverse transcriptase.

doi:10.1371/journal.pone.0011682.g002

DIC2_2.1 rev to determine if an equivalent to Dync1i2 Exon 1 b.D was expressed. The isoform was found in some but not all nervous system tissues, and in embryonic nervous system but not whole embryo. It is the longest Dync1i2(1a) transcript we can detect, being 2,493 bp in length. This isoform does not so far have orthologs in human or rat. The GenBank accession number obtained for this sequence is GU992208 (Table 1).

Dync1i2(1a).E. This novel isoform was detected based on the sequence of Dync1i2(1b).E, in all nervous system tissues except for olfactory bulb, and embryonic tissues, using PCR with primers DIC2_Ex 1a for and DIC2_6 rev and then nested PGR with
DIC2_Ex 1a for and DIC2_2.1 rev and sequencing of the amplified $300 \mathrm{bp}$ product. This isoform does not so far have orthologs in human or rat and we note that Dync1i2(1b).E is a low abundance transcript. The GenBank accession number obtained for this sequence is GU992209 (Table 1).

Dync1i2(1b).E. This novel isoform was found as one clone out of 64 in brain; it has not been detected so far in human transcripts and it may be a low abundance transcript that is specific to the mouse/rat evolutionary branch. The GenBank accession number obtained for this sequence is GU992212 (Table 1). 
Table 3. Summary of mouse dynein intermediate gene 1 splice isoform expression in different mouse tissues.

\begin{tabular}{|c|c|c|c|c|c|c|}
\hline \multicolumn{7}{|l|}{ Dync1i1 } \\
\hline Tissue & Dync1i1.A & Dync1i1.B & Dync1i1.D & Dync1i1.E & Dync1i1.C & Dync1i1.F \\
\hline Whole adult brain & + & + & + & + & + & + \\
\hline Adult spinal cord & + & + & + & + & + & + \\
\hline Adult cortex & + & + & + & + & + & + \\
\hline Adult cerebellum & + & + & + & + & + & + \\
\hline Adult brainstem & + & + & + & + & + & + \\
\hline Adult hippocampus & + & + & + & + & + & + \\
\hline Adult olfactory bulb & + & + & + & + & + & + \\
\hline Whole embryo E17.5 & + & + & + & + & + & $*$ \\
\hline Embryonic brain E17.5 & + & + & + & + & + & + \\
\hline Embryonic spinal cord E17.5 & + & + & + & + & + & $*$ \\
\hline Ovary & & & & & + & \\
\hline Testis & & & & & + & \\
\hline \multicolumn{7}{|l|}{ Spleen } \\
\hline \multicolumn{7}{|l|}{ Kidney } \\
\hline \multicolumn{7}{|l|}{ Lung } \\
\hline \multicolumn{7}{|l|}{ Heart } \\
\hline \multicolumn{7}{|l|}{ Intestine } \\
\hline \multicolumn{7}{|l|}{ Muscle } \\
\hline Liver & & & & & & \\
\hline
\end{tabular}

Dync1i2(1a).A. This isoform was detected in $36 / 75$ brain subclones and 8/82 spinal cord subclones. It corresponds to mouse cDNA ENSMUST00000112140 and has an homologous fulllength human cDNA sequence uc002uha. 1 and is also described by a rat EST CB784025. It is detected by RT-PGR with the primer pairs DIC2_Ex la for and DIC2_R rev, DIC2_Ex 1a for and DIC2_N4 rev, and DIC2_Ex la for and DIC2_6 rev (Table 4).

Dync1i2(1b).A. This isoform was detected in 35/64 brain subclones and 17/72 spinal cord subclones; it corresponds to the human cDNA uc002uhe.1 and rat cDNAs RefSeq NM_053880, and GenBank mRNA U39044. It is amplified by the primer pairs DIC2_Ex $1 \mathrm{~b}$ for and DIC2_R rev, DIC2_Ex $1 \mathrm{~b}$ for and DIC2_N4 rev and DIC2_Ex 1b for and DIC2_6 rev.

Dync1i2(1a).B. This isoform was detected in $16 / 75$ brain subclones and 17/82 spinal cord subclones. It is shorter than isoform Dync1i2(1a).A by $18 \mathrm{bp}$ as a result of removing of exon 4 . This isoform is described by a number of human ESTs (BP228682, BP229314, DA386957, DA488835, DA492636, DA497525，DA694727，DA696722，DA749926，DA769782, DA776852，DB003699，DB038590，DA493266，DA487646, DB173651) and rat EST CF977964. It is detected by primer pairs DIC2_Ex 1a for and DIC2_R rev and DIC2_Ex la for and DIC2_6 rev.

Dync1i2(1b).B. This isoform was detected in 15/64 brain subclones and 23/72 spinal cord subclones. It is shorter than isoform Dync1i2(1b).A by 18 bp as a result of removing of exon 4 and it corresponds to human full-length cDNA uc002uhd.1 and rat GenBank mRNA U39045, ESTs GB711834, GK470011, CV107841 and in mouse is detected by primer pairs DIC2_Ex 1b for and DIC2_R rev, and DIC2_Ex 1b for and DIC2_6 rev.
Dync1i2(1a).F. This novel isoform was detected in $1 / 75$ brain subclones, in mouse only - no corresponding human or rat expressed sequences have been found so far, thus this may be a low abundance isoform or an aberrant splice product without functional significance. This isoform should be detected in mouse with primer pairs DIC2_Ex la for and DIC2_R rev, DIC2_Ex 1a for and DIC2_N4 rev and DIC2_Ex 1a for and DIC2_iso24 rev, however we were not able to detect it in any tissue by PCR. The GenBank accession number obtained for this sequence is GU992210.

Putative Dync1i2(1b).F. We are unable to determine if this exists. We tried several times in each tissue to detect the presence of isoform Dync1i2(1b).F but were consistently unable to do so. We cannot detect it by RT-PCR or in any of our subclones, nor is it present in the current human or rat transcript databases. This may show this isoform is not expressed. However, we note that the Dync1i2 Exon la.F equivalent is also detected at low abundance.

Dync1i2(1a). C. This isoform was detected in 19/75 brain subclones and 53/82 spinal cord subclones and all other tissues, it corresponds to human cDNA uc002uhb.1 and rat ESTs CK365527, EV774963, FM056664. It is detected in mouse with primer pairs DIC2_Ex la for and DIC2_R rev, and DIC2_Ex la for and DIC2_iso24 rev.

Dync1i2(1b).G. This isoform was detected in $13 / 64$ brain subclones and 36/72 spinal cord subclones, and all other tissues, it corresponds to human uc002uhf.1 and rat GenBank mRNA U39046 and ESTs CD568113, CK355960, CK367553, CK471588, CV108862, EV763033, EV774374. It is detected using mouse primers DIC2_Ex 1b for and DIC2_R rev, and DIC2_Ex 1b for and DIC2_iso24 rev. 

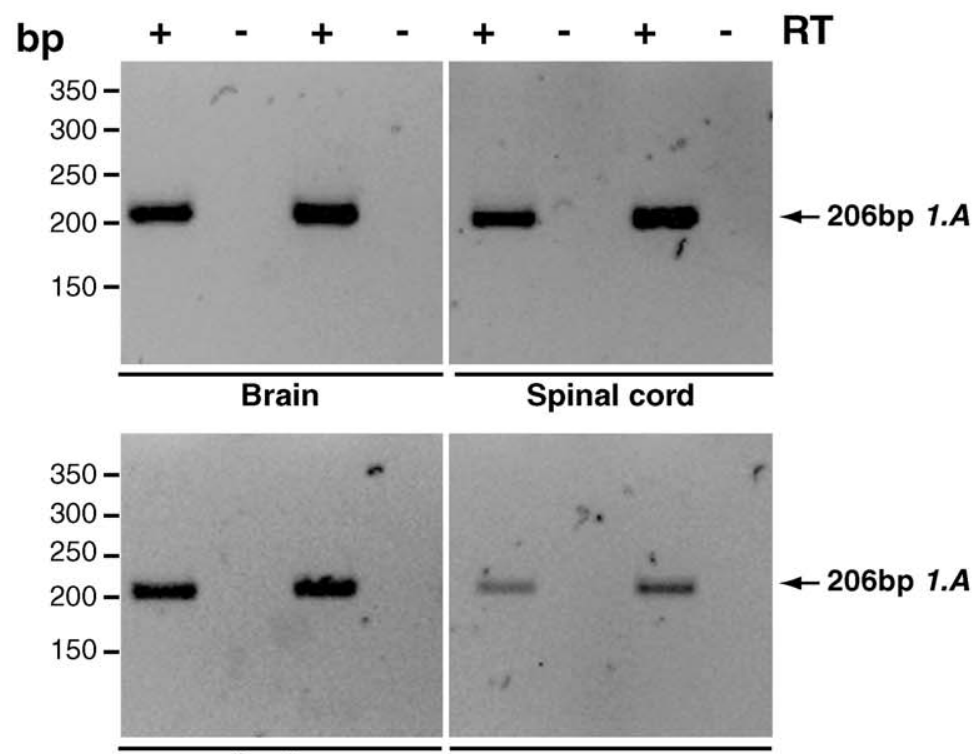

Spinal cord
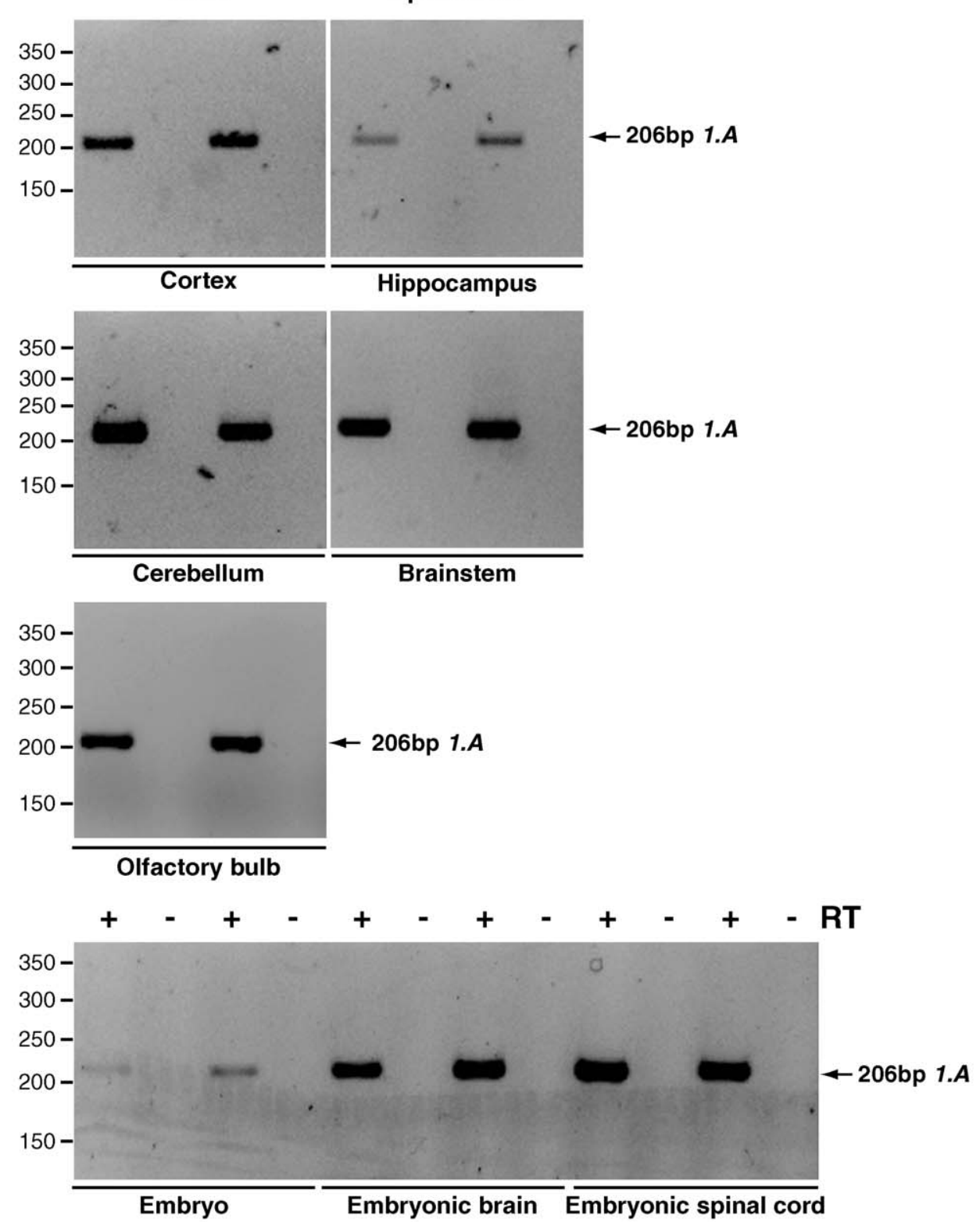

Figure 3. An isoform specific RT-PCR: screening for Dync1i1.A in mouse tissues. Primers DIC1_1.1 for and DIC1_5 rev amplify a 206 bp product from isoform Dync1i1.A. ' + ' lanes are CDNA, ' - ' lanes control for genomic DNA contamination and have no reverse transcriptase. Dync1i1.A is found in all brain regions screened, but may not be highly expressed in the E17.5 whole embryo, although this is not a quantitative PCR (data not shown).

doi:10.1371/journal.pone.0011682.g003 
A

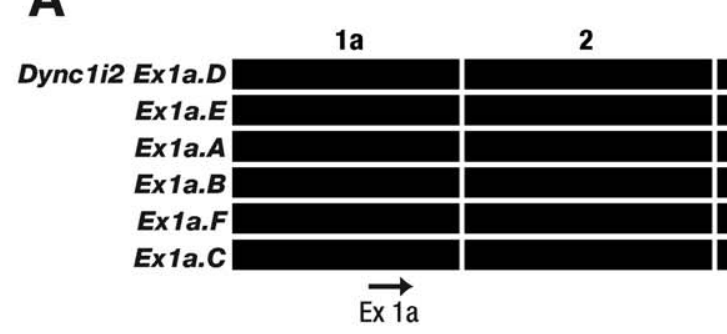

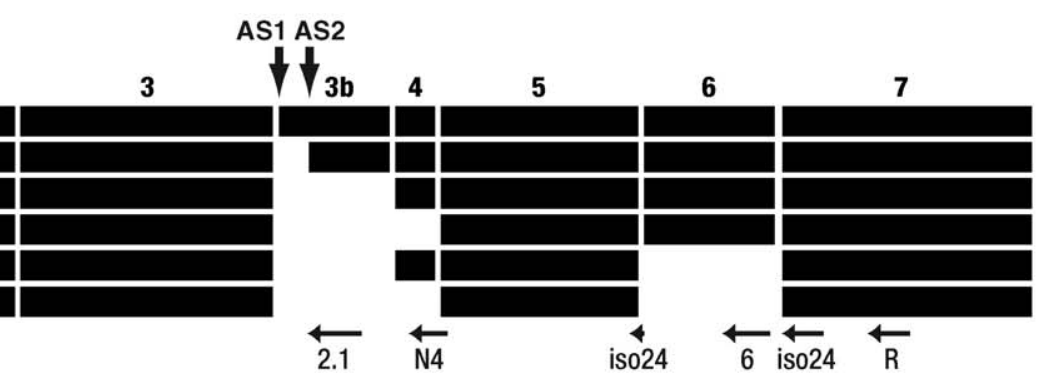

B

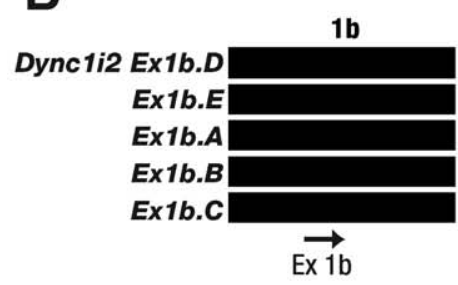

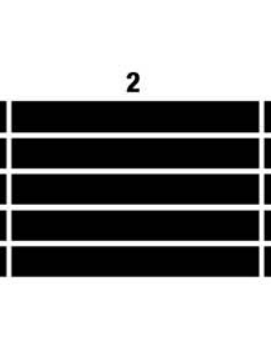

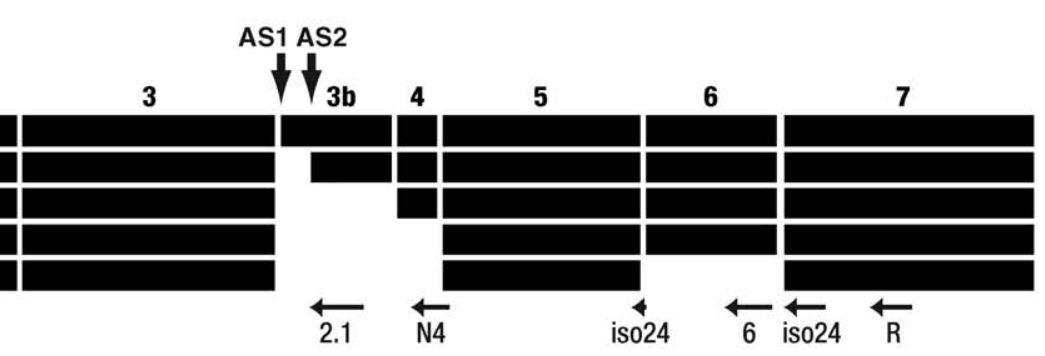

C

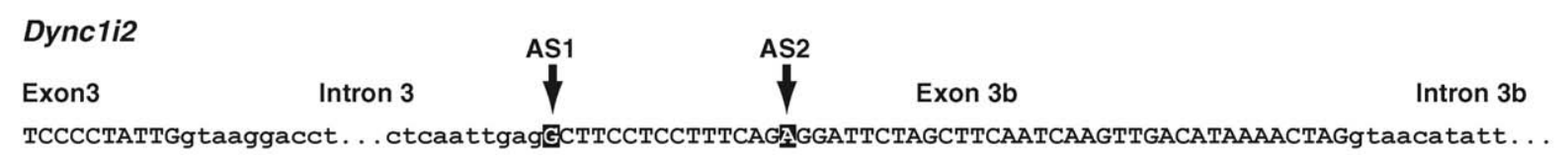

Figure 4. Splicing pattern of mouse dynein intermediate chain $\mathbf{2}$ gene. A, B. Summary of alternative splicing in Dync1i2 with exon $1 \mathrm{a}$ or $1 \mathrm{~b}$ respectively and the first seven exons (numbered $1 a$ or $1 b, 2,3,3 b, 4,5,6,7$ ). Primer binding sites used for isoform specific RT-PCRs are as indicated (Table 4, S2). AS refers to alternative splice sites in exon 3b. Note that we could not detect the presence of the putative Dync1i2(1b).F in any tissue surveyed. Exons are drawn to scale. C. Alternative splice sites in Dync1i2 exon 3b. The nucleotide in bold is the first base pair of the exon. Bases in lower case are intronic, bases in upper case are exonic.

doi:10.1371/journal.pone.0011682.g004

\section{Discussion}

We undertook an extensive survey of the expression of mRNAs of the cytoplasmic dynein intermediate chain genes Dync1i1 and Dync1i2 in a range of mouse tissues. We utilized RT-PCR on mouse transcripts to show the presence of new intermediate chain isoforms in the mouse including those derived from novel exons and non-coding exons. We found the greatest complexity to be present in the adult nervous system. Bioinformatic analyses corroborate the existence of these complex splicing patterns and new isoforms and confirm the similarities between mouse, human and rat. These analyses were performed at the tissue, not cellular, level and other less abundant isoforms may remain to be identified, particularly those expressed earlier in development than E17.5. For example, we detected at a low level from mouse, cDNAs of Dync1i2 isoforms that are deleted for a single glutamine residue in exon 18 (data not shown, Ensembl transcripts ENSMUST00000112136, ENSMUST00000112139), and we find the presence of two other possible new isoforms present as fulllength cDNAs in human (uc010zdt.1 (exon 1a), uc010zds.1 (exon lb), hg19, GRCh37), however, these do not appear to be expressed in mouse or rat (A.Kuta, unpublished). These transcripts contain an exon 5 which is 54 bp longer than the exon 5 shown here because of the use of an upstream alternative $3^{\prime}$ splice site; and at the same time exons 4 and 6 are excluded, which results in a protein of 630 amino acids in length.

Prior to this work, the distribution and expression of intermediate chain splice isoforms had been best studied in the rat $[21,22,23,24]$. However, dynein intermediate chain splice isoforms are not restricted to mammals or vertebrates. For example, complex splicing patterns are found in the homologous intermediate chain gene in Drosophila, Cdic [25] and these patterns arise from alternative splicing of three small exons located between exons 4 and 5 of this gene. This strongly suggests that alternative splicing of the N-terminal region of the intermediate chains is essential for some aspect of eukaryotic dynein motor protein function in cells.

\section{Alternative $5^{\prime}$ non coding exons in Dync1i2}

The presence of two alternative $5^{\prime}$ non-coding first exons in Dync1i2 is intriguing and suggests another complex layer of regulation. We detected differences in the relative expression levels of Dyncli2 isoforms depending on whether exon la or $1 \mathrm{~b}$ was spliced into the transcript (Table 5); for example see the expression of Dync1i2(1a).E and 2(1b).E in adult brain and whole embryo (Figure 7). As the human and mouse genomes are analyzed an increasing number of genes are found to have alternative non-coding first exons [26]. Recent studies in human have found approximately $50 \%$ of genes have at least one alternative promoter and such genes tend to have significantly longer genomic structures including $5^{\prime}$ and $3^{\prime}$ UTRs, intron and exon lengths and numbers of exons compared to genes with single promoters ([27] and references therein). Interestingly Dync1i1 is a significantly longer gene than Dync1i2, but so far we can find no evidence for it having an alternative non-coding $5^{\prime}$ exon. The use of alternative promoters is thought to be associated with cellspecific expression; for example the human CYP19 aromatase gene has at least 10 alternative non-coding first exons [28] which appear to control mRNA stability and gene expression [29]. 
Table 4. Primer pairs used to amplify individual Dync1i2 splice isoforms (Figure 4).

\begin{tabular}{|c|c|c|}
\hline \multicolumn{3}{|l|}{ Dync1i2 exon 1a splice isoforms } \\
\hline Primer pair & $\begin{array}{l}\text { Isoform } \\
\text { detected }\end{array}$ & $\begin{array}{l}\text { Predicted } \\
\text { bands }\end{array}$ \\
\hline DIC2_Ex 1a for and DIC2_R rev & $\begin{array}{l}\text { Dync1i2(1a).D } \\
\text { Dync1i2(1a).E } \\
\text { Dync1i2(1a).A } \\
\text { Dync1i2(1a).B } \\
\text { (Dync1i2(1a).F) } \\
\text { Dync1i2(1a).C }\end{array}$ & $\begin{array}{l}556 \text { bp } \\
541 \text { bp } \\
505 \text { bp } \\
487 \text { bp } \\
445 \text { bp } \\
427 \text { bp }\end{array}$ \\
\hline DIC2_Ex 1a for and DIC2_2.1 rev & $\begin{array}{l}\text { Dync1i2(1a).D } \\
\text { Dync1i2(1a).E }\end{array}$ & $\begin{array}{l}315 b p \\
300 b p\end{array}$ \\
\hline DIC2_Ex 1a for and DIC2_N4 rev & $\begin{array}{l}\text { Dync1i2(1a).D } \\
\text { Dync1i2(1a).E } \\
\text { Dync1i2(1a).A } \\
\text { (Dync1i2(1a).F) }\end{array}$ & $\begin{array}{l}352 \mathrm{bp} \\
337 \mathrm{bp} \\
301 \mathrm{bp} \\
301 \mathrm{bp}\end{array}$ \\
\hline DIC2_Ex 1a for and DIC2_6 rev & $\begin{array}{l}\text { Dync1i2(1a).D } \\
\text { Dync1i2(1a).E } \\
\text { Dync1i2(1a).A } \\
\text { Dync1i2(1a).B }\end{array}$ & $\begin{array}{l}496 \mathrm{bp} \\
481 \mathrm{bp} \\
445 \mathrm{bp} \\
427 \mathrm{bp}\end{array}$ \\
\hline DIC2_Ex 1a for and DIC2_iso24 rev & $\begin{array}{l}\text { (Dync1i2(1a).F) } \\
\text { Dync1i2(1a).C }\end{array}$ & $\begin{array}{l}405 b p \\
387 b p\end{array}$ \\
\hline \multicolumn{3}{|l|}{ Dync1i2 exon 1b splice isoforms } \\
\hline DIC2_Ex 1b for and DIC2_R rev & $\begin{array}{l}\text { Dync1i2(1b).D } \\
\text { Dync1i2(1b).E } \\
\text { Dync1i2(1b).A } \\
\text { Dync1i2(1b).B } \\
\text { (Dync1i2(1b).F) } \\
\text { Dync1i2(1b).C }\end{array}$ & $\begin{array}{l}581 \mathrm{bp} \\
566 \mathrm{bp} \\
531 \mathrm{bp} \\
513 \mathrm{bp} \\
(471 \mathrm{bp}) \\
453 \mathrm{bp}\end{array}$ \\
\hline DIC2_Ex 1b for and DIC2_2.1 rev & $\begin{array}{l}\text { Dync1i2(1b).D } \\
\text { Dync1i2(1b).E }\end{array}$ & $\begin{array}{l}340 \mathrm{bp} \\
325 \mathrm{bp}\end{array}$ \\
\hline DIC2_Ex 1b for and DIC2_N4 rev & $\begin{array}{l}\text { Dync1i2(1b).D } \\
\text { Dync1i2(1b).E } \\
\text { Dync1i2(1b).A } \\
\text { (Dync1i2(1b).F) }\end{array}$ & $\begin{array}{l}378 \text { bp } \\
363 \text { bp } \\
(327 \mathrm{bp})\end{array}$ \\
\hline DIC2_Ex 1b for and DIC2_6 rev & $\begin{array}{l}\text { Dync1i2(1b).D } \\
\text { Dync1i2(1b).E } \\
\text { Dync1i2(1b).A } \\
\text { Dync1i2(1b).B }\end{array}$ & $\begin{array}{l}522 \mathrm{bp} \\
507 \mathrm{bp} \\
471 \mathrm{bp} \\
453 \mathrm{bp}\end{array}$ \\
\hline DIC2_Ex 1b for and DIC2_iso24 rev & $\begin{array}{l}\text { (Dync1i2(1b).F) } \\
\text { Dync1i2(1b).C }\end{array}$ & $\begin{array}{l}\text { (431 bp) } \\
413 \mathrm{bp}\end{array}$ \\
\hline
\end{tabular}

Note that we have been unable to detect the Dync1i2 exon 1b.F. doi:10.1371/journal.pone.0011682.t004

Similarly, the use of three (in mouse and human) or two (in rat) alternative promoters resulting in the expression of alternative non-coding first exons has been shown for GATA4 gene [30].

\section{Significance of the different intermediate chain isoforms}

We have shown that different tissues express different intermediate chain isoforms. All of the Dync1i1 isoforms were found only in nervous tissue, with the exception of Dync1i1.C, which was also found in ovary and testis. This result is consistent with previous studies in rat that found that all the IC1 isoforms are expressed exclusively in the nervous system, except that one was found in testis, and ovary was not examined, [21,22,23]. We further found that most mouse tissues express only the IC2C isoforms; this is different from rat, where most tissues express both IC2C and IC2B [21,22,23].

While our RT-PCR results are not quantitative, there are clearly reproducible differences between tissues, and our studies further indicate the isoforms also expressed at different levels in different tissues. Further, preliminary data using fluorescent primers and capillary gel electrophoresis to determine the relative amounts of each amplicon in the total amplified pool, showed tissue specific differences in expression (Kuta, A. unpublished). The patterns we see consistently show that when RT-PCR results for Dync1i1 and Dync1i2 isoforms are compared between different brain regions the relative proportions of the different isoforms are different (for example, see Figures 2, 5).

Most of the splice isoform complexity we observed for both intermediate chains is within the nervous system tissue. This is consistent with the previously published data from rat where all six identified intermediate chain isoform were expressed in the adult brain. In rat, the analysis of the expression of the isoforms was extended to the cellular level and these data demonstrated that the basis for the complexity was in the neurons. Cultured embryonic cortical and hippocampal neurons expressed the IC1B, 1C, 2B, and $2 \mathrm{C}$ isoforms. All other cultured cells, including glia, expressed only the IC2C isoform, except that IC2B was found in neuroblastomas [22,23,31].

The cytoplasmic dynein complex is involved in many processes including protein and RNA transport, organelle trafficking, as well as mitosis, endosome sorting, and the cellular stress response and response to hypoxia. The neuronal intermediate chain complexity may reflect the dependence of axonal and cellular survival on the efficient transport of trophic and other factors from the synapse to the cell body (often over $1 \mathrm{~m}$ in length) $[32,11,33]$. It also may reflect the complexity of the different types of cargoes that have to be actively transported within neurons, both in the adult and in the developing embryo. Axonal transport must be a highly regulated and ordered process to transport such disparate organelles and cargo. While the precise role of the intermediate chains in dynein regulation in these processes is not completely understood, it is known that dynein complexes with specific intermediate chains are responsible for the transport of individual organelles. For example dynein complexes with IC1B, are necessary for the transport of Trk signalling endosomes in rat hippocampal axons $[10,21,22,23]$. At the minimum, the intermediate chain isoforms produce functionally distinct classes of dynein complexes that may be separately regulated to carry different specific cargoes.

Consistent with a role for the intermediate chains in neuron specific function, we clearly observed differences in the expression of intermediate chain isoforms when the patterns from late embryonic and adult brain are compared. In rat only the generic IC2C was found at E13, but with increasing embryonic age, first IC2B and then IC1B and $1 \mathrm{C}$ were found. While the IC2A and $1 \mathrm{~A}$ isoforms were found only in the adult (P20 and older) [23]. Using probes for specific for common regions of IC1 and IC2, Crackower and colleagues investigated dynein intermediate chain expression in mouse embryos at different stages of development using whole mount in situ hybridization. They found that at mouse E10.5-13.5 Dync1i1 was restricted to the developing cortex and the peripheral nervous system (dorsal root ganglia and sympathetic ganglia), while Dync1i2 was more widely expressed within the nervous system [34]. In addition Dyncli2 was found to be highly expressed a non neuronal tissue, the mouse developing limb bud [34], and may play a role in establishing cell polarity by orientating intracellular components correctly $[35,3]$.

\section{Relationship between exons and protein domains for dynein intermediate chains}

The intermediate chains have a scaffold-like role in the dynein complex. They dimerize and bind to the dynein heavy chain, the three light chain dimers, and the putative cargo adaptor, dynactin. The intermediate chains and the light chains, with 

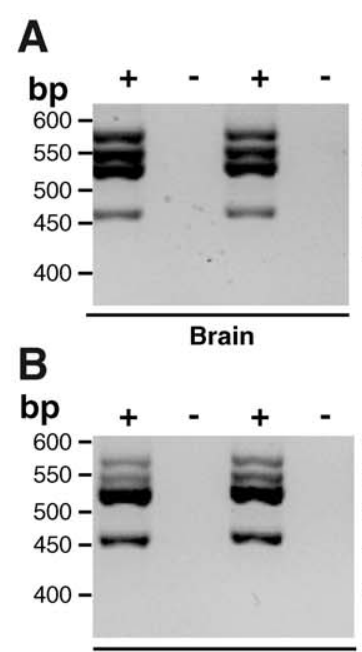

Spinal cord
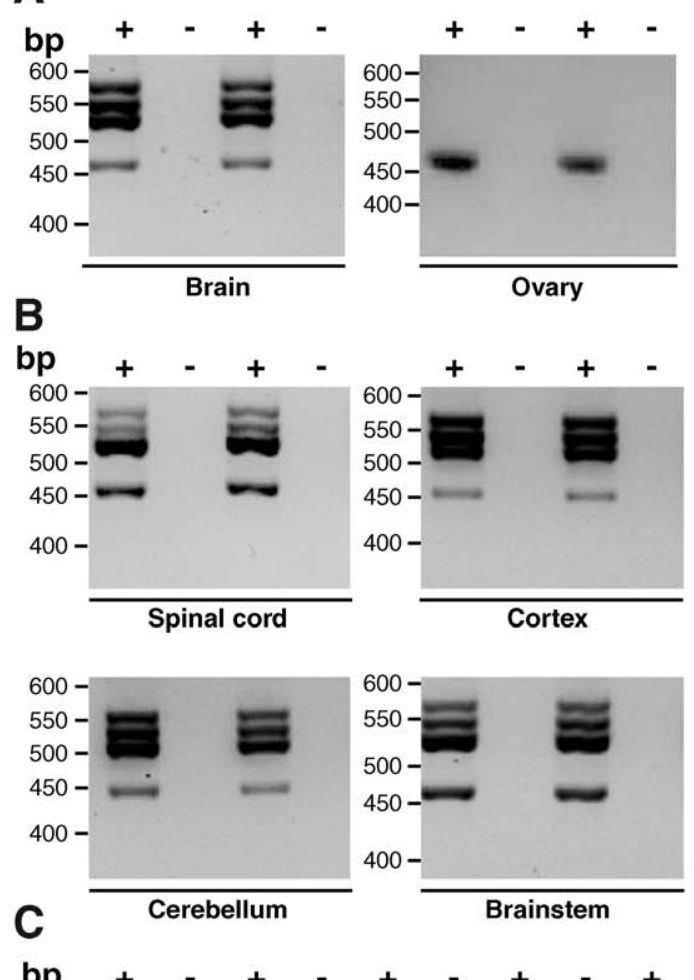

Ovary
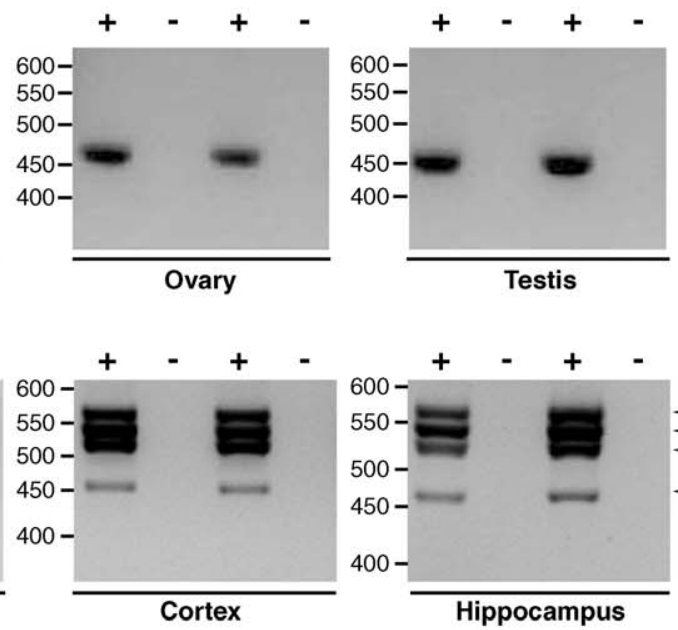

Testis

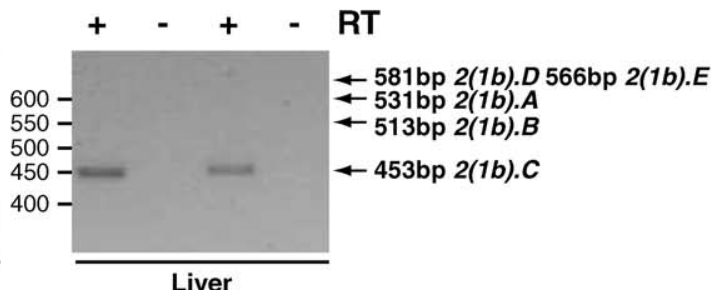

Liver

RT

$\leftarrow 581 \mathrm{bp} 2(1 \mathrm{~b}) \cdot \mathrm{D} 566 \mathrm{bp} 2(1 \mathrm{~b}) . \mathrm{E}$

$\leftarrow 531 \mathrm{bp} 2(1 \mathrm{~b}) \cdot A$

$\leftarrow 453$ bp 2 (1b). $C$

Hippocampus

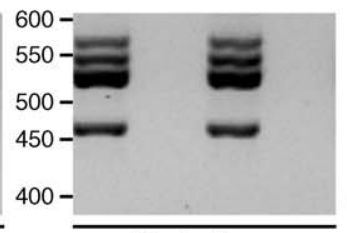

Brainstem

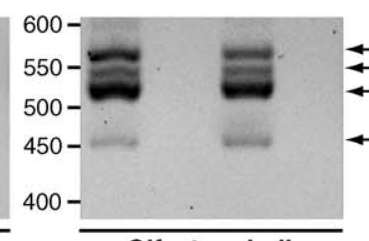

Olfactory bulb

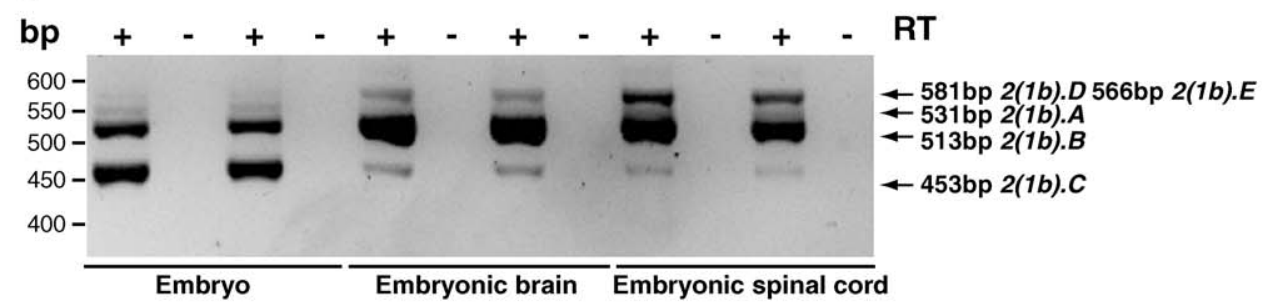

Figure 5. Amplification of different isoforms of Dync1i2 Exon 1b in mouse tissues using one primer pair. Isoforms of Dync1i2 Exon $1 \mathrm{~b}$ were amplified in mouse tissues using primer pair DIC2_Ex $1 \mathrm{~b}$ for and DIC2_R rev which produce five products: Dync1i2.D (581 bp), Dync1i2.E (566 bp), Dync1i2.A (531 bp), Dync1i2.B (513 bp) and Dync1i2.C (453 bp). Dync1i2.D (581 bp) is not resolved from Dync1i2.E (566 bp) due to the similar length of PCR products; therefore we undertook nested PCRs with primers DIC2_Ex 1b for and DIC2_2.1 rev to determine the transcription pattern of these two isoforms (data not shown). We did not detect 2(1b).F in this assay. A. Adult tissues: brain, ovary, testis and liver. In brain five amplicons are detected as shown (and confirmed by nested PCRs). In ovary, testis and liver we detect isoform Dync1i2.C only. B. Adult neuronal tissues: In spinal cord, cortex, hippocampus, cerebellum, brainstem and olfactory bulb five amplicons are detected as shown. C. Embryonic tissues: Three or five amplicons are detected as shown.

doi:10.1371/journal.pone.0011682.g005

the light intermediate chains, form the cargo binding domain of the cytoplasmic dynein complex $[3,36,37]$. The intermediate chain $\mathrm{N}$-terminal region forms a coiled-coil which interacts with p150 subunit of dynactin [24]. At the C-terminal lies seven WD40 repeats which are thought to form a $\beta$ propeller structure responsible for interaction with the dynein heavy chain $[20,38]$. Proximal to the WD repeats are the binding sites for the dynein light chains and the dimerisation domain [19,8,39,40,41]. As can be seen in Figure 8, (the position of domains in the longest DYNG1I1 and DYNC1I2 isoforms are shown in Table S3) the exon structure for these major functional domains is similar between the IC1 and IC2 proteins. The alternative splice isoforms of IC1 and IC2 affect the region of the protein downstream of the N-terminal coiled coli region and upstream of the region binding to DYNLT and DYNLL light chains, between exons $3 \mathrm{~b} / 4$ and exon 5. This region of the N-terminus has been implicated in binding of the p150 subunit of dynactin, and it is rich in serines and threonines, leading to suggestions that one function of the alternative splicing is to generate novel phosphorylation sites that are important for specific dynein regulation, for example in modifying binding to the p150 subunit of dynactin, or other putative cargo adaptors [24,42]. Our observation that there is only $8.7 \%$ identity between IC1 exon $4^{*}$ (the fragment of exon 4 spanning between the start of this exon and the AS2 site) and IC2 exons 3B and 4 compared to greater than $51 \%$ identity for other exons (Figure 8D) shows that this region is one of significant variability between the intermediate chains and it is consistent with the hypothesis that this region of the intermediate chains may have an important role in dynein regulation.

\section{Conclusion}

The mechanisms of how dynein intermediate chains contribute to the specificity of dynein function and its regulation are poorly understood. To better understand intermediate chain variation, we have characterized in detail the alternative splicing of the two cytoplasmic dynein intermediate chains genes in the mouse. We have identified new splicing patterns, a novel exon, and the presence of two distinct first exons in Dync1i2. Mouse genetic 


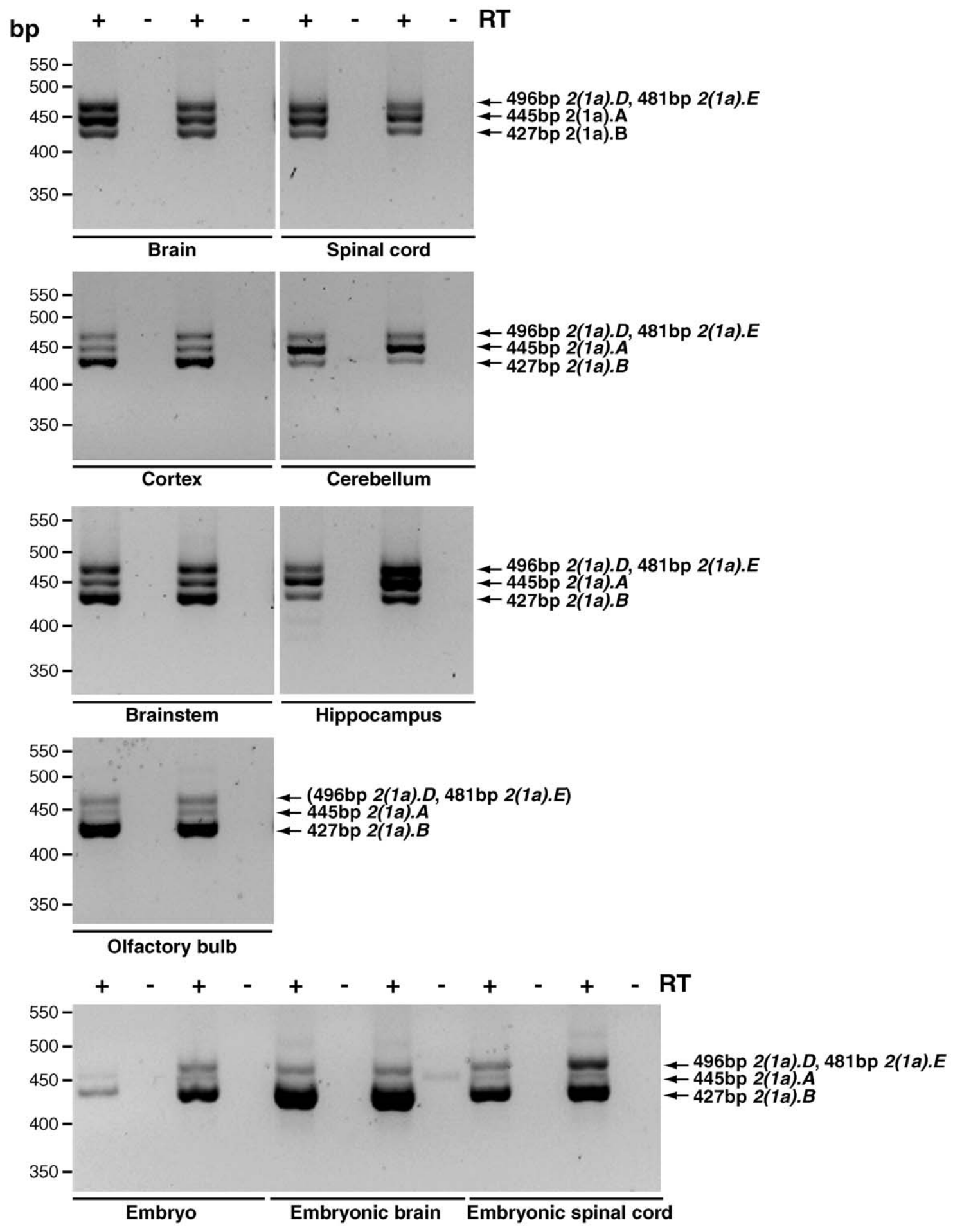

Figure 6. Examples of Dync1i2 Exon 1a isoform specific PCR. Four isoforms of Dync1i2 Exon1a are amplified in the mouse nervous system and E17.5 embryonic nervous tissues using primer pair DIC2_Ex1a for and DIC2_6 rev. Amplicons are as shown and in addition while Dync1i2(1a).D was not resolved in this amplification it was amplified as shown in Table 5 using primers DIC2_Ex 1a for and DIC2_2.1 rev (data not shown). We were unable to resolve, even by nested PCR, which of isoforms Dync1i2(1a).D and Dync1i2(1a).E were present in olfactory bulb. '+' lanes are cDNA, '-' lanes control for genomic DNA contamination and have no reverse transcriptase.

doi:10.1371/journal.pone.0011682.g006

studies have shown that neurons are particularly dependent on the efficient function of cytoplasmic dynein. Consistent with this we have further shown that in the mouse the expression pattern of intermediate chain alternative splicing is richest (or more complex) in neural tissue. This work has important implications for the regulation of cytoplasmic dynein in neurons and will allow additional experiments to further probe the mechanisms of neuronal dynein regulation. 
Table 5. Summary of mouse dynein intermediate gene 2 splice isoform expression in different mouse tissues.

\begin{tabular}{|c|c|c|c|c|c|c|}
\hline \multicolumn{7}{|l|}{ Dync1i2 Exon 1a } \\
\hline Tissue & Dync1i2.D & Dync1i2.E & Dync1i2.A & Dync1i2.B & Dync1i2.C & Dync1i2.F \\
\hline Whole adult brain & & + & + & + & + & + \\
\hline Adult spinal cord & + & + & + & + & + & \\
\hline Adult cortex & + & + & + & + & + & \\
\hline Adult cerebellum & & + & + & + & + & \\
\hline Adult brainstem & + & + & + & + & + & \\
\hline Adult hippocampus & & + & + & + & + & \\
\hline Adult olfactory bulb & & & + & + & + & \\
\hline Whole embryo E17.5 & & & + & + & + & \\
\hline Embryonic brain E17.5 & + & + & + & + & + & \\
\hline Embryonic spinal cord E17.5 & + & + & + & + & + & \\
\hline Ovary & & & & & + & \\
\hline Testis & & & & & + & \\
\hline Spleen & & & & & + & \\
\hline Kidney & & & & & + & \\
\hline Lung & & & & & + & \\
\hline Heart & & & & & + & \\
\hline Intestine & & & & & + & \\
\hline Muscle & & & & & + & \\
\hline Liver & & & & & + & \\
\hline \multicolumn{7}{|l|}{ Dync1i2 Exon 1b } \\
\hline Tissue & Dync1i2.D & Dync1i2.E & Dync1i2.A & Dync1i2.B & Dync1i2.C & \\
\hline Whole adult brain & + & + & + & + & + & \\
\hline Adult spinal cord & + & + & + & + & + & \\
\hline Adult cortex & & + & + & + & + & \\
\hline Adult cerebellum & + & + & + & + & + & \\
\hline Adult brainstem & + & + & + & + & + & \\
\hline Adult hippocampus & + & + & + & + & + & \\
\hline Adult olfactory bulb & + & + & + & + & + & \\
\hline Whole embryo E17.5 & & + & + & + & + & \\
\hline Embryonic brain E17.5 & & + & + & + & + & \\
\hline Embryonic spinal cord E17.5 & & + & + & + & + & \\
\hline Ovary & & & & & + & \\
\hline Testis & & & & & + & \\
\hline Spleen & & & & & + & \\
\hline Kidney & & & & & + & \\
\hline Lung & & & & & + & \\
\hline Heart & & & & & + & \\
\hline Intestine & & & & & + & \\
\hline Muscle & & & & & + & \\
\hline Liver & & & & & + & \\
\hline
\end{tabular}

No differences were detected in male and female samples, thus results are not broken down by sex.

doi:10.1371/journal.pone.0011682.t005

\section{Materials and Methods}

\section{Mouse tissues}

All tissues were collected from C57BL/6J inbred mice, supplied by Harlan Laboratories. Mice were housed in controlled conditions in accordance with guidance issued by the Medical
Research Council in Responsibility in the Use of Animals for Medical Research (1993) and all experiments were carried out under Licence from the UK Home Office and with full ethical approval from the MRC Prion Unit Local Ethical Review Panel.

For RNA extraction tissues were collected from 2 male and 2 female mice aged 6-8 weeks (brain, spinal cord, ovary, testis, 


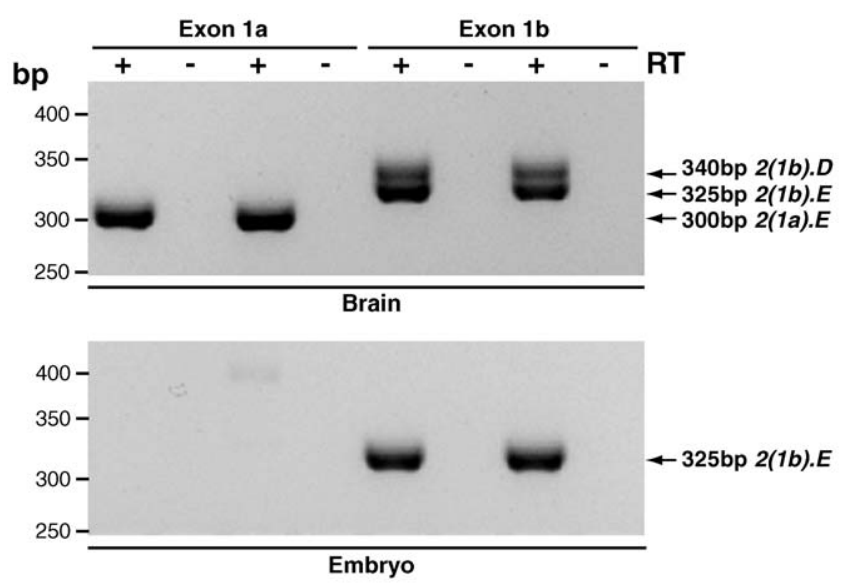

Figure 7. Differential expression of Dync1i2 with exon 1a and exon $1 b$ containing isoforms. Brain CDNA was amplified by nested RT-PCR with exon 1a primers DIC2_Ex 1a for and DIC2_2.1 rev which amplify 2(1a).D (315bp) and 2(1a).E (300bp), and with exon $1 \mathrm{~b}$ primers DIC2_Ex 1b for and DIC2_2.1 rev which amplify 2(1b).D (340bp) and 2(1b).E (325bp). We detect Dync1i2.E containing exons 1a or 1b; we detect Dync1i2.D containing exon $1 \mathrm{~b}$ only and not exon 1a, showing differential expression of this isoform depending on which first noncoding exon is spliced in the adult brain. E17.5 whole embryo CDNA was amplified the same primer pairs (DIC2_Ex1a and DIC2 2.1 rev, and DIC2_Ex 1b and DIC2_2.1rev). We detect no Dync1i2.D isoforms. However, we detect 2(1b).E but not 2(1a).E, showing differential expression of Dync1i2.E depending on which first non-coding exon is spliced in.

doi:10.1371/journal.pone.0011682.g007

spleen, lung, kidney, heart, intestine, muscle, liver). Brain was also collected from 2 male and 2 female mice aged 6-8 weeks and was dissected into cortex, hippocampus, cerebellum, brainstem, olfactory bulb. Immediately after dissection tissues were placed in RNAse free $1.5 \mathrm{ml}$ tubes (Biopur, Eppendorf) and immersed in RNAlater reagent (Qiagen) to minimize RNA degradation. Tissues were stored at $4^{\circ} \mathrm{C}$ overnight and transferred to $-80^{\circ} \mathrm{C}$ for long term storage.

For RNA extraction from embryonic tissues, timed matings were set up by placing a male overnight with females and removing the male the following day. Embryos were collected from terminally anaesthetized pregnant females at E17, and 2 whole embryos and 2 embryonic brain and spinal cords were collected for this study as above.

\section{RNA preparation}

Tissues were weighed and RNA Mini Kits (Qiagen) were used to extract total RNA from mouse tissues according to manufacturer's instructions, in RNAse-free conditions.

\section{Preparation of muscle and liver RNA}

We found muscle and liver gave poor quality preparations, possibly owing to either the fibrous nature of these tissues or high lipid content in liver, therefore we modified the RNA preparation for these tissues by homogenizing them in TRIreagent (Sigma) at $1 \mathrm{ml}$ per $30 \mathrm{mg}$ tissue. Homogenates were centrifuged at $4^{\circ} \mathrm{C}$ for $30 \mathrm{~min}$ at $5,000 \times \mathrm{g}$, and supernatant was transferred to a fresh tube for treatment with RNAse free Mussel Glygogen (Sigma) for $5 \mathrm{~min}$ at a final concentration of $250 \mathrm{ug} / \mathrm{ml}$, room temperature, after which $0.1 \mathrm{ml}$ bromo-chloro-propane (BCP, Sigma) per $1 \mathrm{ml}$ of TRIreagent was added, the mixture was shaken vigorously and incubated for 2-3 min at room temperature. After centrifugation at $4^{\circ} \mathrm{C}$ for $30 \mathrm{~min}$ at $5,000 \times \mathrm{g}$ the lysate separated into into 3 phases. The upper aqueous phase was carefully transferred to a fresh tube and $0.3 \mathrm{ml}$ isopropanol and $0.2 \mathrm{ml}$ high salt solution (0.8M sodium citrate, $1.2 \mathrm{M}$ sodium chloride) per $1 \mathrm{ml}$ of TRIreagent were added, followed by incubation for $10 \mathrm{~min}$ at room temperature. After centrifugation $\left(4^{\circ} \mathrm{C}\right.$ for $30 \mathrm{~min}$ at $5,000 \times \mathrm{g})$ RNA precipitated at the bottom of the tube and was washed with $75 \%$ ethanol (VWR), volume equal to TRIreagent, and centrifuged $\left(4^{\circ} \mathrm{C}\right.$ for $30 \mathrm{~min}$ at $\left.5,000 \times \mathrm{g}\right)$. Supernatant was removed and $1 \mathrm{ml} 75 \%$ ethanol was added. The $75 \%$ ethanol plus pellet were transferred to an RNAse free $1.5 \mathrm{ml}$ tube (Biopur, Eppendorf), centrifuged at room temperature at $14,000 \times \mathrm{g}$ for $5 \mathrm{~min}$ and the supernatant carefully removed. The RNA pellet was air dried and resuspended in $30 \mathrm{ul}$ RNAse free water. Subsequently total RNA was purified with DNAse digest using an RNeasy Mini Kit (Qiagen) according to manufacturer's instructions in RNAse-free conditions.

\section{RNA quantification}

Quantity and purity of RNA were determined using a NanoDrop ${ }^{\circledR}$ ND-1000 Spectrophotometer (Labtech) by measuring absorbance at $260 \mathrm{~nm}$ and $280 \mathrm{~nm}\left(\mathrm{OD}_{260}, \mathrm{OD}_{280}\right)$. The instrument was blanked against water and UV measurements of $1.4 \mathrm{ul}$ RNA samples were taken and the $\mathrm{OD}_{260 / 280}$ ratio and RNA concentrations $\left(\mathrm{OD}_{260}\right.$ of $\left.1.0=40 \mathrm{ug} / \mathrm{ml} \mathrm{RNA}\right)$ were automatically computed using the NanoDrop ${ }^{\circledR}$ software. RNA purity was assessed by $\mathrm{OD}_{260 / 280}$ ratio, with acceptable values lying above 1.9 .

\section{Formaldehyde agarose gel electrophoresis}

RNA quality was checked by formaldehyde agarose gel electrophoresis; $1.2 \%$ agarose gel was prepared by mixing $10 \mathrm{ml}$ $10 \times$ FA buffer $(200 \mathrm{mM}$ MOPS, $50 \mathrm{mM}$ sodium acetate, $10 \mathrm{mM}$ EDTA, pH 7.0) with $90 \mathrm{ml}$ RNAse free water. Agarose was microwaved at high power for $1-2 \mathrm{~min}$, cooled to $60^{\circ} \mathrm{C}$ and

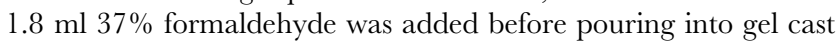
tray. RNA samples and RNA Ladder (Sigma-Aldrich) were mixed with $2 \times$ concentrated RNA Loading Buffer containing ethidium bromide (Sigma-Aldrich) and incubated at $65^{\circ} \mathrm{C}$ for $5 \mathrm{~min}$ to denature possible secondary structures and rapidly chilled on ice. Samples were loaded and electrophoresed in $1 \times$ FA running

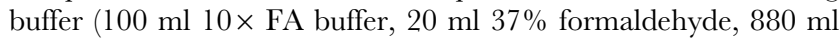
$\left.\mathrm{H}_{2} \mathrm{O}\right)$ at $7 \mathrm{~V} / \mathrm{cm}$. Post-electrophoresis, gels were visualized and imaged on a UV transilluminator and digital imaging system (BioRad Laboratories).

\section{cDNA preparation}

A master mix containing $400 \mathrm{ng}$ total RNA, $25 \mathrm{ng} / \mathrm{ul}$ oligo dT primer, $4 \mathrm{mM}$ dNTPs and AccuScript buffer (Stratagene) to $17 \mathrm{ul}$ was incubated at $65^{\circ} \mathrm{C}$ for $5 \mathrm{~min}$ and cooled to room temperature for 10 mins to allow primer annealing; DTT was added to $10 \mathrm{mM}$ and AccuScript Reverse Transcriptase (Stratagene) was added according to the manufacturer's protocol to a final volume of $20 \mathrm{ul}$; negative control reactions were also prepared where the addition of reverse transcriptase was omitted. The reaction mix was incubated at $42^{\circ} \mathrm{C}$ for $45 \mathrm{~min}$ to produce cDNA. Aliquots were diluted 1:10 for long term storage.

\section{Reverse transcription - Polymerase Chain Reaction (RT-PCR)}

All the reactions were performed on a DNA Engine Tetrad 2 Peltier Thermal Cycler (BioRad Laboratories). A list of primers used in different applications is described in Table S2. PCRs were set up with 10 times diluted cDNAs prepared as described 

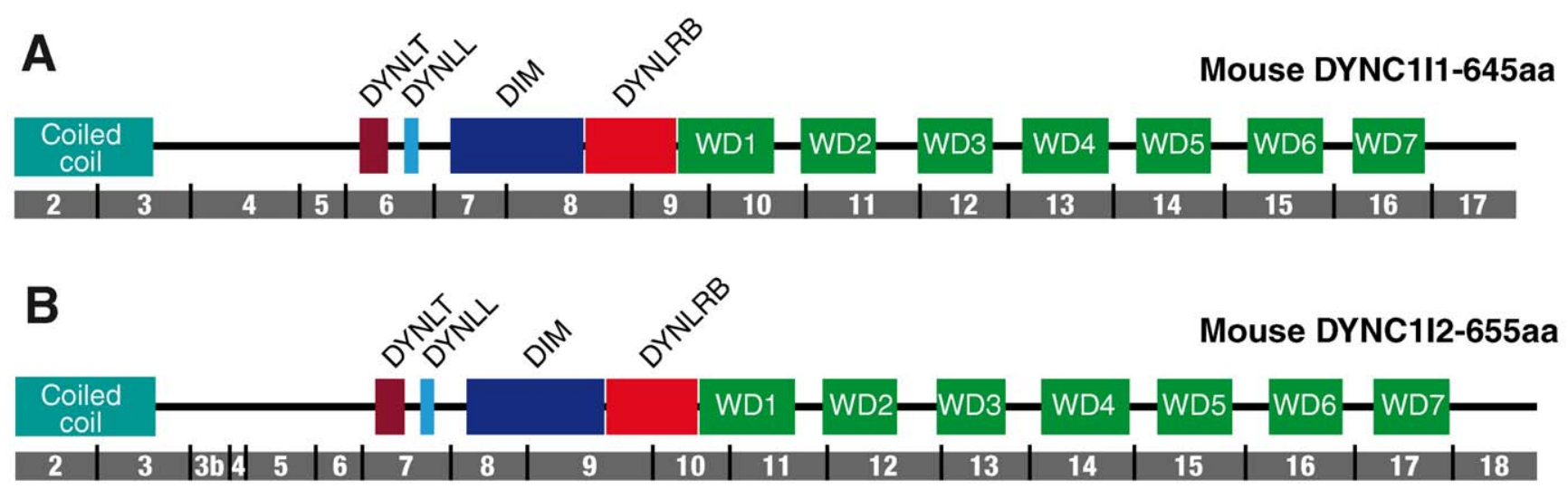

$120 \quad 40 \quad 60 \quad 80100120140160180200220240260280300320340360380400420440460480500520540560580600620640655$

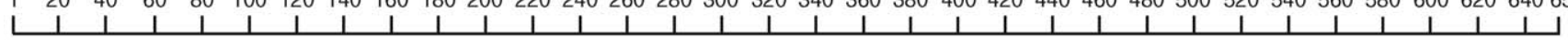

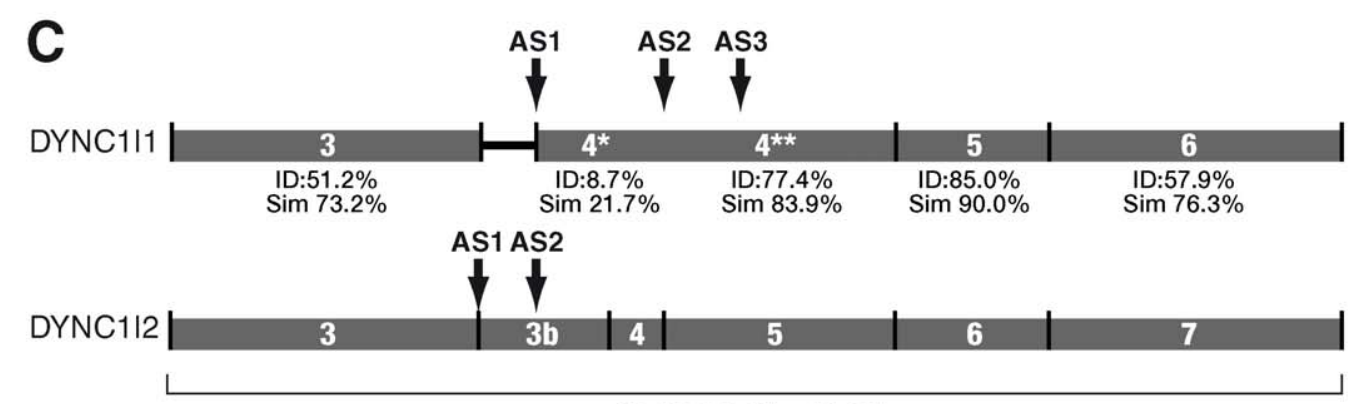

ID: $56.3 \% \operatorname{Sim} 71.5 \%$

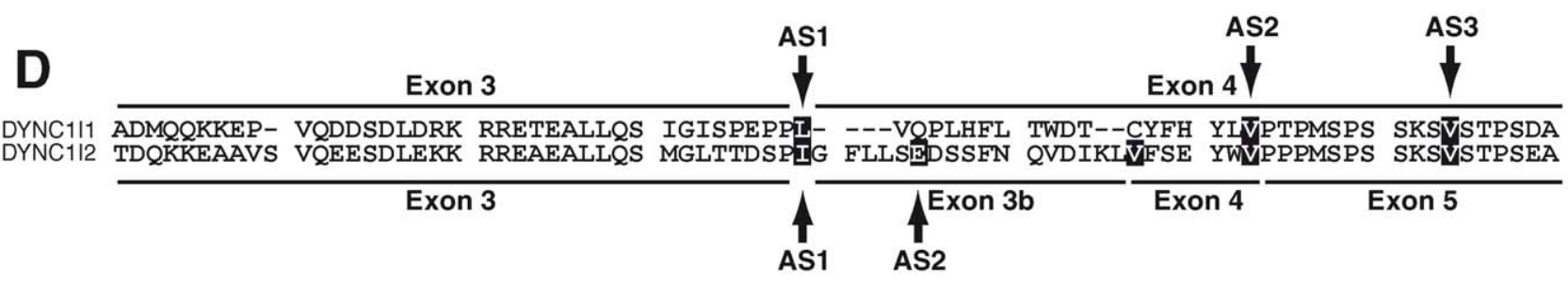

Exon 4

Exon 5

Exon 6

DYNC111 GSODSGDLGP LTRTLQWDTD PSVLQLOSDS ELGRRLHKLG VSKVTQVDFL PREVVSYSKE TQTPLATHQS E DYNC112 GSQDSGDGAV GSRTLHWDTD PSVLQLHSDS DIERGPIKLG MAKITQVDFP PREIVTYTKE TQTPVTAQPK E
Exon 5
Exon 6
Exon 7

Figure 8. Exon - protein domain relationship for dynein intermediate chain genes. Protein domains marked as blocks, numbered exons marked in grey. The coiled coil region where protein interactions occur is shown as is DYNLT - binding region of Tctex dynein light chains, DYNLL binding region of LC8 dynein light chains, DIM - intermediate chain dimerisation domain, DYNLRB - binding domain of Roadblock dynein light chains; seven WD40 repeats marked in green. The domain boundaries are as shown in Table S3 [19,8,20,39,40,24,41]. A. Mouse DYNC111 isoform 1.A (645 amino acids). B. Mouse DYNC112 isoform 2.D (655 amino acids). Note that isoform 2.D includes exons 1 to 3 and new exon 3b; exon 4 to 18. C. Schematic alignment of DYNC111 and DYNC112 protein sequences coded by exons 3 to 6 of Dync1i1 and exons 3 to 7 of Dync 1 i2 genes; alternative splice sites in Dync1i1 exon 4 (AS1, AS2, AS3) and Dync1i2 exon 3b (AS1, AS2) are marked. The percent of identity (ID) and similarity (Sim) between segments of protein sequences coded by specific exons were compared using AliSubSimP. Protein sequences of DYNC111 and DYNC112 encoded by exons 3 are $51.2 \%$ identical and $73.2 \%$ similar; protein sequence of DYNC111 exon 4 was compared as two segments marked with asterix: $4^{*}$ from AS1 to AS2 and $4^{* *}$ from AS2 to the end of exon 4 . There is only $8.7 \%$ identity and $21.7 \%$ similarity between Dync 111 exon $4 *$ and DYNC112 exons $3 \mathrm{~b}$ and 4 while DYNC111 exon $4^{* *}$ and DYNC1/2 exon 5 show $77.4 \%$ identity and $83.9 \%$ similarity. Furthermore, DYNC1/1 exon 5 is $85.0 \%$ identical and $90.0 \%$ similar to DYNC112 exon 6. Protein sequences of DYNC111 encoded by exon 6 and DYNC112 encoded by exon 7 are $57.9 \%$ identical and $76.3 \%$ similar. The whole fragments of the intermediate chains presented show $56.3 \%$ identity and $71.5 \%$ similarity. D. Alignment of DYNC111 and DYNC1/2 protein sequences encoded by exons 3 to 6 of Dync1i1 and exons 3 to 7 of Dync1i2 genes; alternative splice sites in Dync1i1 exon 4 (AS1, AS2, AS3) and in Dync1i2 exon 3b (AS1, AS2) marked, amino acids shaded overlap splice sites.

doi:10.1371/journal.pone.0011682.g008

above, the amount of cDNA was normalized to the ng of RNA used in Reverse Transcriptase reaction. Conditions used were annealing temperature of $58^{\circ} \mathrm{C}$ for 30 s, and elongation at $68^{\circ} \mathrm{C}$ for 3 minutes over 35 cycles using Pfu High Fidelity Polymerase
(Stratagene) according to manufacturer's instructions. For multiplex reactions a Multiplex PCR Kit (Qiagen) was used according to manufacturer's instructions with an annealing temperature of $60^{\circ} \mathrm{C}$ for $90 \mathrm{sec}$, elongation at $72^{\circ} \mathrm{C}$ for $1 \mathrm{~min}$ 
over 35 cycles. PGR products were purified using QIAquick PGR purification kits (Qiagen) according to manufacturer's instructions. PCR products were visualized by electrophoresis on agarose gels in $1 \times$ TBE buffer (National Diagnostics) according to standard protocols. The quality of cDNA obtained was checked by amplifying a 780bp product from the mouse Gapdh gene which is ubiquitously expressed (Figure S3).

\section{Subcloning cDNAs}

After amplification PGR products were subcloned into the pCR4-TOPO ${ }^{\circledR}$ vector (Invitrogen) using a TOPO TA kit (Invitrogen) according to manufacturer's instructions.

\section{Sequencing}

Automated fluorescence sequencing was carried out with a BigDye Terminator Ready Reaction Kit (Applied Biosystems) on a 3130XL Genetic Analyser (Applied Biosystems) according to manufacturer's protocols.

\section{Bioinformatics analysis}

We searched the UCSC Genome Browser which is developed and maintained by the Genome Bioinformatics Group within the Center for Biomolecular Science and Engineering at the University of California Santa Cruz (UCSC); the 2009 update describes 46 genome assemblies for including those for human (assembly hg19, October 2009), mouse (assembly mm9, July 2007), rat (assembly rn4, November 2004, EST database update October 2008), with extensive comparative genomics tools (Kuhn et al. 2009). Transcripts assigned as permanent have an 'uc' accession number. The mouse transcripts of Dyncli1 and Dync1i2 were also compared with entries found in the Ensembl Genome Browser release 57 (3 March 2010). ESTs mentioned in the text were those which extend from exon 1 sufficiently far into the cDNA (Dynclil or Dyncli2) to determine which isoform they represented.

We used several tracks within the UCSC Genome Browser to help identify possible splice variants in mouse including:

UCSG 'Known Genes'. All UCSG Gene tracks show gene predictions based on data from RefSeq (NCBI RNA reference sequences), GenBank, CCDS (Consensus Coding DNA Sequences) and UniProt, thus they are a moderately conservative set of predictions, requiring the support of one GenBank RNA sequence plus at least one additional line of evidence (e.g. a UniProt, 'Exoniphy' prediction, or two or more expressed sequence tags (ESTs)). The RefSeq RNAs do not require additional evidence. Thus tracks include both protein-coding and putative non-coding transcripts, and compared to RefSeq genes contain more splice variants.

Database of Transcription Start Sites. DBTSS (http:// dbtss.hgc.jp/, release 6.0.1) is a database of transcriptional start sites (TSS), based on an unique collection of precise, experimentally-determined 5 '-end sequences of full-length cDNAs [26]. The use of an oligo-capping technique allows TSS to be assigned to independent genomic positions to which the first bases of sequenced cDNA were mapped, thus most cDNA sequence $5^{\prime}$ ends should correspond to active TSSs [43].

Transcription Factor Binding Sites. The HMR (Human, Mouse, Rat) conserved transcription factor binding sites track in the UCSC Genome Browser contains the location and score of transcription factor binding sites conserved in the human/mouse/ rat alignment. A binding site is considered to be conserved if its score meets the threshold score for its binding matrix in all 3 species. The score and threshold are computed with the Transfac Matrix Database (v7.0) created by Biobase (http://www.gene- regulation.com/pub/databases.html). The data are purely computational, and as such not all binding sites listed are biologically functional. The analysis presented here was only undertaken for sites upstream to the transcription start (exon 1) for both Dync1i1 and Dync1i2.

Target Scan. The Target Scan miRNA regulatory sites track of the UCSG Genome Browser shows conserved mammalian microRNA regulatory target sites in the $3^{\prime}$ UTR regions of Refseq Genes, as predicted by TargetScan [44]. Putative miRNA binding sites in UTRs were identified using seven-nucleotide seed regions from all known miRNA families conserved among human, mouse, rat, dog and sometimes chicken [45].

Protein sequence analysis. Protein sequences were aligned using ClustalW2 (http://srs.ebi.ac.uk) with Gonnet set as a substitution matrix. Subsequently they were compared using AliSubSimP (http://srs.ebi.ac.uk) with EBLOSUM62 as a scoring matrix.

\section{Supporting Information}

Figure S1 Example of amplifying Dync1i1.C in non-neuronal mouse tissues. Primers DIC1 Ex1 for and DIC1_R rev amplify all six Dyncli1 isoforms (see Figure 2), however in non-neuronal tissues we detect isoform Dync1i1.C only (420bp) in ovary and testis. '+' lanes are cDNA, '-' lanes control for genomic DNA contamination and have no reverse transcriptase.

Found at: doi:10.1371/journal.pone.0011682.s001 (0.86 MB TIF)

Figure S2 Amplification of Dync1i1.F in mouse neuronal tissues. Primers DIC1_1.1 for and DIC1_iso14 rev amplify a 155 bp product from isoform 1.F. One sample in hippocampus and one in cortex failed to amplify. '十' lanes are cDNA, '-' lanes control for genomic DNA contamination and have no reverse transcriptase. Found at: doi:10.1371/journal.pone.0011682.s002 (3.82 MB TIF)

Figure S3 Example of Gapdh amplicon in mouse tissues. Gapdh is ubiquitously expressed and a single band of $780 \mathrm{bp}$ was visualised in 'reverse transcriptase positive' samples while no bands were visible in samples in which no reverse transcriptase had been added. This was our control for cDNA quality.

Found at: doi:10.1371/journal.pone.0011682.s003 (2.47 MB TIF)

Table S1 Exon intron boundaries of mouse Dync $1 i 1$ and Dync1i2. Found at: doi:10.1371/journal.pone.0011682.s004 (0.02 MB DOCX)

Table S2 Primer sequences used to determine the splicing pattern of Dync1i1 and Dync1i2.

Found at: doi:10.1371/journal.pone.0011682.s005 (0.01 MB DOCX)

Table S3 The position of protein domains in the longest DYNC1I1 and DYNC1I2 isoforms.

Found at: doi:10.1371/journal.pone.0011682.s006 (0.01 MB DOCX)

\section{Acknowledgments}

We thank Frances Wiseman and Virginie Bros Facer for help with sample preparation, Dalia Kasperaviciute and Mike Mitchell (GRUK) for bioinformatics advice and Ray Young for graphics.

\section{Author Contributions}

Conceived and designed the experiments: AK MH EMF. Performed the experiments: AK WD AMEK GTB MH. Analyzed the data: AK KKP. Contributed reagents/materials/analysis tools: AK WD AMEK GTB MH. Wrote the paper: AK KKP EMF. 


\section{References}

1. Hook P, Vallee RB (2006) The dynein family at a glance. J Cell Sci 119: $4369-4371$.

2. Pfister KK, Fisher EM, Gibbons IR, Hays TS, Holzbaur EL, et al. (2005) Cytoplasmic dynein nomenclature. J Cell Biol 171: 411-413.

3. Pfister KK, Shah PR, Hummerich H, Russ A, Cotton J, et al. (2006) Genetic analysis of the cytoplasmic dynein subunit families. PLoS Genet 2: el.

4. Levy JR, Holzbaur EL (2006) Cytoplasmic dynein/dynactin function and dysfunction in motor neurons. Int J Dev Neurosci 24: 103-111.

5. Gennerich A, Carter AP, Reck-Peterson SL, Vale RD (2007) Force-induced bidirectional stepping of cytoplasmic dynein. Cell 131: 952-965.

6. Paschal BM, Mikami A, Pfister KK, Vallee RB (1992) Homology of the 74-kD cytoplasmic dynein subunit with a flagellar dynein polypeptide suggests an intracellular targeting function. J Cell Biol 118: 1133-1143.

7. Kardon JR, Vale RD (2009) Regulators of the cytoplasmic dynein motor. Nat Rev Mol Cell Biol 10: 854-865.

8. Lo KW, Kogoy JM, Rasoul BA, King SM, Pfister KK (2007) Interaction of the DYNLT (TCTEX1/RP3) light chains and the intermediate chains reveals novel intersubunit regulation during assembly of the dynein complex. J Biol Chem 282: $36871-36878$.

9. Tynan SH, Purohit A, Doxsey SJ, Vallee RB (2000) Light intermediate chain 1 defines a functional subfraction of cytoplasmic dynein which binds to pericentrin. J Biol Chem 275: 32763-32768.

10. Ha J, Lo KW, Myers KR, Carr TM, Humsi MK, et al. (2008) A neuron-specific cytoplasmic dynein isoform preferentially transports TrkB signaling endosomes. J Cell Biol 181: 1027-1039.

11. Chevalier-Larsen E, Holzbaur EL (2006) Axonal transport and neurodegenerative disease. Biochim Biophys Acta 1762: 1094-1108.

12. Schroer TA (2004) Dynactin. Annu Rev Cell Dev Biol 20: 759-779.

13. Ligon LA, Karki S, Tokito M, Holzbaur EL (2001) Dynein binds to beta-catenin and may tether microtubules at adherens junctions. Nat Cell Biol 3: 913-917.

14. Karki S, Tokito MK, Holzbaur EL (1997) Casein kinase II binds to and phosphorylates cytoplasmic dynein. J Biol Chem 272: 5887-5891.

15. Wagner OI, Ascano J, Tokito M, Leterrier JF, Janmey PA, et al. (2004) The interaction of neurofilaments with the microtubule motor cytoplasmic dynein. Mol Biol Cell 15: 5092-5100.

16. Ligon LA, Tokito M, Finklestein JM, Grossman FE, Holzbaur EL (2004) A direct interaction between cytoplasmic dynein and kinesin I may coordinate motor activity. J Biol Chem 279: 19201-19208.

17. Caviston JP, Ross JL, Antony SM, Tokito M, Holzbaur EL (2007) Huntingtin facilitates dynein/dynactin-mediated vesicle transport. Proc Natl Acad Sci U S A 104: 10045-10050.

18. Paschal BM, King SM, Moss AG, Collins CA, Vallee RB, et al. (1987) Isolated flagellar outer arm dynein translocates brain microtubules in vitro. Nature 330: 672-674.

19. Lo KW, Kan HM, Pfister KK (2006) Identification of a novel region of the cytoplasmic Dynein intermediate chain important for dimerization in the absence of the light chains. J Biol Chem 281: 9552-9559.

20. Ma S, Trivinos-Lagos L, Graf R, Chisholm RL (1999) Dynein intermediate chain mediated dynein-dynactin interaction is required for interphase microtubule organization and centrosome replication and separation in Dictyostelium. J Cell Biol 147: 1261-1274.

21. Myers KR, Lo KW, Lye RJ, Kogoy JM, Soura V, et al. (2007) Intermediate chain subunit as a probe for cytoplasmic dynein function: biochemical analyses and live cell imaging in PC12 cells. J Neurosci Res 85: 2640-2647.

22. Pfister KK, Salata MW, Dillman JF III, Vaughan KT, Vallee RB, et al. (1996) Differential expression and phosphorylation of the 74-kDa intermediate chains of cytoplasmic dynein in cultured neurons and glia. J Biol Chem 271: 1687-1694.

23. Pfister KK, Salata MW, Dillman JF III, Torre E, Lye RJ (1996) Identification and developmental regulation of a neuron-specific subunit of cytoplasmic dynein. Mol Biol Cell 7: 331-343.

24. Vaughan KT, Vallee RB (1995) Cytoplasmic dynein binds dynactin through a direct interaction between the intermediate chains and p150Glued. J Cell Biol 131: $1507-1516$
25. Nurminsky DI, Nurminskaya MV, Benevolenskaya EV, Shevelyov YY, Hartl DL, et al. (1998) Cytoplasmic dynein intermediate-chain isoforms with different targeting properties created by tissue-specific alternative splicing. Mol Cell Biol 18: 6816-6825.

26. Wakaguri H, Yamashita R, Suzuki Y, Sugano S, Nakai K (2008) DBTSS: database of transcription start sites, progress report 2008. Nucleic Acids Res 36: D97-101.

27. Liu S (2010) Increasing alternative promoter repertories is positively associated with differential expression and disease susceptibility. PLoS ONE 5: e9482.

28. Bulun SE, Sebastian S, Takayama K, Suzuki T, Sasano H, et al. (2003) The human CYP19 (aromatase P450) gene: update on physiologic roles and genomic organization of promoters. J Steroid Biochem Mol Biol 86: 219-224.

29. Wang H, Li R, Hu Y (2009) The alternative noncoding exons 1 of aromatase (Cyp19) gene modulate gene expression in a posttranscriptional manner. Endocrinology 150: 3301-3307.

30. Mazaud GS, Bouchard MF, Robert-Grenon JP, Robert C, Goodyer CG, et al. (2009) Conserved usage of alternative 5' untranslated exons of the GATA4 gene. PLOS ONE 4: e8454.

31. Salata MW, Dillman JF III, Lye RJ, Pfister KK (2001) Growth factor regulation of cytoplasmic dynein intermediate chain subunit expression preceding neurite extension. J Neurosci Res 65: 408-416.

32. Banks GT, Fisher EM (2008) Cytoplasmic dynein could be key to understanding neurodegeneration. Genome Biol 9: 214

33. Hafezparast M, Klocke R, Ruhrberg C, Marquardt A, Ahmad-Annuar A, et al. (2003) Mutations in dynein link motor neuron degeneration to defects in retrograde transport. Science 300: 808-812.

34. Crackower MA, Sinasac DS, Xia J, Motoyama J, Prochazka M, et al. (1999) Cloning and characterization of two cytoplasmic dynein intermediate chain genes in mouse and human. Genomics 55: 257-267.

35. Levin M, Nascone N (1997) Two molecular models of initial left-right asymmetry generation. Med Hypotheses 49: 429-435.

36. Benison G, Karplus PA, Barbar E (2007) Structure and dynamics of LC8 complexes with KXTQT-motif peptides: swallow and dynein intermediate chain compete for a common site. J Mol Biol 371: 457-468.

37. Towns WL, Tauhata SB, Vaughan PS, Vaughan KT (2009) Transfectioninduced defects in dynein-driven transport: evidence that ICs mediate cargobinding. Cell Motil Cytoskeleton 66: 80-89.

38. Yang P, Sale WS (1998) The Mr 140,000 intermediate chain of Chlamydomonas flagellar inner arm dynein is a WD-repeat protein implicated in dynein arm anchoring. Mol Biol Cell 9: 3335-3349.

39. Mok YK, Lo KW, Zhang M (2001) Structure of Tctex-1 and its interaction with cytoplasmic dynein intermediate chain. J Biol Chem 276: 14067-14074.

40. Susalka SJ, Nikulina K, Salata MW, Vaughan PS, King SM, et al. (2002) The roadblock light chain binds a novel region of the cytoplasmic Dynein intermediate chain. J Biol Chem 277: 32939-32946.

41. Williams JC, Roulhac PL, Roy AG, Vallee RB, Fitzgerald MC, et al. (2007) Structural and thermodynamic characterization of a cytoplasmic dynein light chain-intermediate chain complex. Proc Natl Acad Sci U S A 104: 10028-10033.

42. Whyte J, Bader JR, Tauhata SB, Raycroft M, Hornick J, et al. (2008) Phosphorylation regulates targeting of cytoplasmic dynein to kinetochores during mitosis. J Cell Biol 183: 819-834.

43. Kimura K, Wakamatsu A, Suzuki Y, Ota T, Nishikawa T, et al. (2006) Diversification of transcriptional modulation: large-scale identification and characterization of putative alternative promoters of human genes. Genome Res 16: 55-65.

44. Lewis BP, Burge CB, Bartel DP (2005) Conserved seed pairing, often flanked by adenosines, indicates that thousands of human genes are microRNA targets. Cell 120: 15-20.

45. Grimson A, Farh KK, Johnston WK, Garrett-Engele P, Lim LP, et al. (2007) MicroRNA targeting specificity in mammals: determinants beyond seed pairing. Mol Cell 27: 91-105. 